\title{
Understanding cliff use at the New River Gorge National River: combining visitor observations and resource impact assessments
}

D. Kyle Olcott

West Virginia University

Follow this and additional works at: https://researchrepository.wvu.edu/etd

\section{Recommended Citation}

Olcott, D. Kyle, "Understanding cliff use at the New River Gorge National River: combining visitor observations and resource impact assessments" (2011). Graduate Theses, Dissertations, and Problem Reports. 3431.

https://researchrepository.wvu.edu/etd/3431

This Thesis is protected by copyright and/or related rights. It has been brought to you by the The Research Repository @ WVU with permission from the rights-holder(s). You are free to use this Thesis in any way that is permitted by the copyright and related rights legislation that applies to your use. For other uses you must obtain permission from the rights-holder(s) directly, unless additional rights are indicated by a Creative Commons license in the record and/ or on the work itself. This Thesis has been accepted for inclusion in WVU Graduate Theses, Dissertations, and Problem Reports collection by an authorized administrator of The Research Repository @ WVU. For more information, please contact researchrepository@mail.wvu.edu. 
UNDERSTANDING CLIFF USE AT THE NEW RIVER GORGE NATIONAL RIVER: COMBINING VISITOR OBSERVATIONS AND RESOURCE IMPACT ASSESSMENTS

D. Kyle Olcott

Thesis submitted to the Davis College of Agriculture, Natural Resources, and Design at West Virginia University in partial fulfillment of the requirements for the degree of

Master of Science in Forestry

Recreation, Parks and Tourism Resources

Thesis Committee:

Dr. David Smaldone, Chair, Dr. Chad Pierskalla, and Dr. Robert Burns

Morgantown, West Virginia

2011

Keywords: recreation impacts, rock climbing, cliff studies, observation 


\begin{abstract}
Understanding Cliff Use at the New River Gorge National River: Combining Visitor

Observations and Resource Impact Assessments

D. Kyle Olcott
\end{abstract}

The New River Gorge National River (NERI) is managed by the National Park Service (NPS). In addition to being an extremely popular destination for whitewater rafting, it is also home to world class rock climbing and an extensive array of cliffs offering over 2400 routes. This thesis is part of a larger study of the cliffs at NERI, funded by the NPS and encompassing botanic and geologic components in addition to the recreation management component. By combining unobtrusive visitor observation methods with GPS mapping and rapid assessment of nearly 450 areas of impact, a few key management recommendations are made for NERI. Climbing routes closer to fixed top anchor points had a significantly skewed distribution toward more severe impact ratings. Climbers and hikers were found to have a significantly different length of stay, but no significant differences were found in number of depreciative behaviors or group size. The types of depreciative behaviors were different between both groups, and also different among different types of climbers. Potential management implications are discussed, and include suggestions to restrict the number and locations of fixed top anchors and bolted anchors in general, place limitations on areas where top-rope climbing and rappelling are allowed, as well as a "no top out" policy and a restriction on anchoring to trees. 
Acknowledgements

This thesis would not have been possible without the generous funding provided by the National Park Service (NPS). The hard work of the park biologist at the New River Gorge National Scenic River (NERI), John Perez, was instrumental in the creation and execution of this study. My advisor, Dr. David Smaldone, was also indispensible in supporting this work and providing me with this opportunity. I would also like to thank the other members of my thesis committee, Dr. Chad Pierskalla and Dr. Robert Burns, for their advice and unwavering support.

The West Virginia GIS Technical Center was also instrumental in this project through their generous provision of a high-tech GPS unit. Kurt Donaldson, Kevin Kuhn, and Evan Fedorko were all extremely helpful, and without their support I would not have had the proper equipment to do this study.

My wife Katelyn Olcott provided saintly patience and assistance throughout the study and beyond. Additionally, my in-laws, Keith and Tamara Huffman, were true heroes for providing a place to stay near the study area. Without their support this project would certainly not have been possible.

I would also like to thank Dr. Paul Gregory and all of the other professors I had at Washington and Lee University during my undergraduate work some years ago. They gave me a very solid foundation upon which to build a career of scholarship and provided models of fantastic teaching that I seek to emulate. Additionally, all of the scout leaders from my youth helped instill in me a love of the outdoors and a sense of responsibility for my impacts. They long ago planted the seeds that have blossomed into a full-fledged calling to work in the study of outdoor recreation.

Lastly, I would like to thank my parents, Dudley and Kimberley Olcott, for continuing to encourage and support my endeavors, as they have throughout my life. Without their sacrifices and patience I would certainly not be where I am today. 
Table of Contents

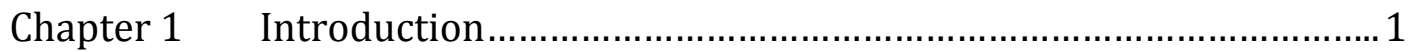

Chapter 2 Literature Review................................................................... 4

Chapter 3 Methods............................................................................ 19

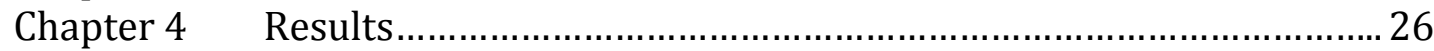

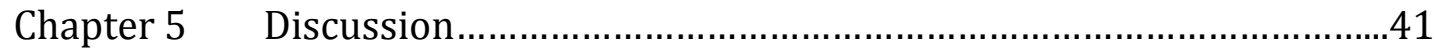

References.................................................................... 50

Appendix

Observation Data Sheet............................................................................53

Figures

Figure 1: $\quad$ Downstream view from Ram's Head...............................2

Figure 2: $\quad$ Map of observation locations..........................................21

Figure 3: $\quad$ Boxplot comparing length of stay by user type.................28

Figure 4: $\quad$ Boxplot comparing length of stay by location....................28

Figure 5: $\quad$ Photos of tree damage at Diamond Point............................30

Figure 6: $\quad$ Pie charts representing climber subtype observations.....31

Figure 7: $\quad$ Photo of climber anchoring to tree at Junkyard Wall......... 32

Figure 8: $\quad$ Photos of fixed top anchors at Endless Wall.......................34

Figure 9: $\quad$ Map of all nodes of use and top anchors.............................35

Figure 10: $\quad$ Map of all nodes of use by climbing area.............................36

Figure 11: $\quad$ Condition class distribution for all nodes of use.................37

Figure 12: $\quad$ Condition class distribution by distance from anchor...... 38

Figure 13: $\quad$ Condition class distribution by bolted or nonbolted..........39

Figure 14: $\quad$ Photo of Ram's Head, heavily impacted area.................... 42

Figure 15: $\quad$ Photo of less impacted area at Beauty Mountain............... 43

Figure 16: Photos of human impacts at NERI.................................... 47

Tables

Table 1: $\quad$ Example of a condition class rating system for trails........ 16

Table 2: $\quad$ Example of a condition class rating system for nodes.......23

Table 3: $\quad$ Visitor Observation Descriptive Data Summary................27

Table $4 \quad$ ANOVA for depreciative behaviors................................... 27

Table 5: $\quad$ ANOVA for length of stay............................................. 27

Table 6: $\quad$ Observed depreciative behaviors by user type...................30

Table 7: $\quad$ Observed depreciative behaviors by type of climber........ 31

Table 8: $\quad$ Summary of Chi-Square tests of node condition class.......39 


\section{Chapter 1 Introduction}

The New River Gorge National River (NERI) is located just east of Beckley, West Virginia (about 60 miles southeast of Charleston). It is managed by the National Park Service (NPS), and encompasses an area of over 70,000 acres extending along 53 miles of the New River. The area is an extremely popular destination for recreational activities such as white water rafting, hiking, and rock climbing. NERI is also home to 11 rare species of plants and animals, as well as the federally endangered Virginia big-eared bat and Indiana bat (NPS, 2009). A nearly continuous cliff band (Figure 1) extends along both sides of the river, affording opportunities for day hiking/sightseeing and rock climbing. Consequently, there are miles of formal and informal day hiking trails along the cliffs. There are also over 2400 rock-climbing routes in NERI and the immediate surrounding area (Williams, 2010). NERI is a nationally known destination for rock climbing, attracting visitors from across the USA (Attarian, 1998). Accordingly, this cliff resource is one of the main attractions at NERI, with particular areas receiving very heavy use.

Like other cliff ecosystems, the cliffs at NERI provide habitat for several endemic and/or sensitive plant and animal species. Various types of recreation users also frequent the cliff areas, particularly day hikers and rock climbers. Rock climbing in particular has greatly increased in popularity in recent years (Larson, Matthes, \& Kelly, 2005). Because of this, NPS managers are concerned about the condition of the cliff resource at NERI in light of their dual mission of preservation and recreation. 


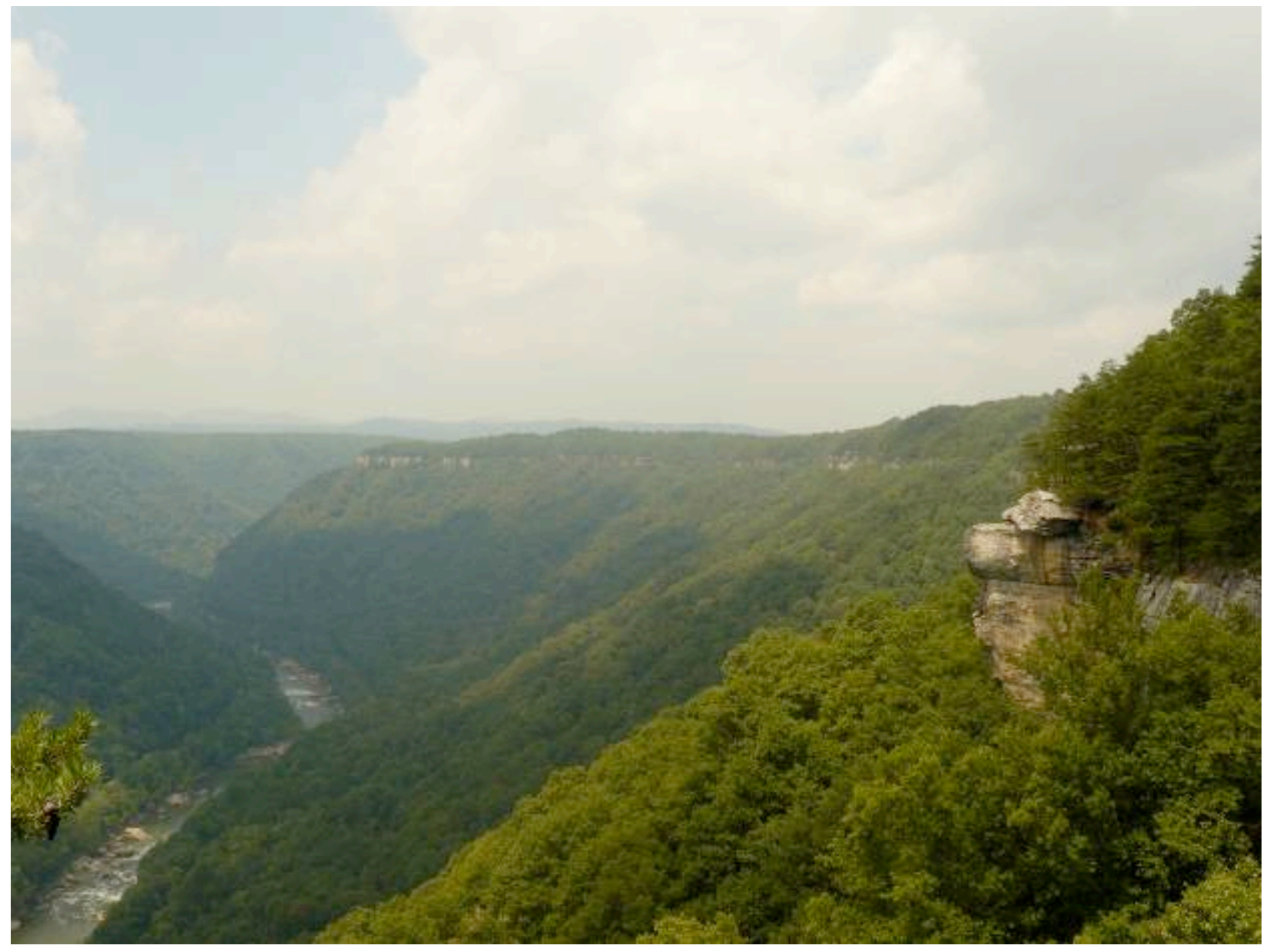

Figure 1: Downstream view from Ram's Head, Diamond Point is visible in the distance

This thesis is part of a research project funded by the NPS to do a large-scale assessment of cliff resources, including social, geological, and botanical components. The project is a multi-year, interdisciplinary effort with the goal of ultimately giving NERI managers the information they need to make scientifically sound decisions regarding cliff usage. This thesis is based mostly on the first phase of the social component, which includes direct visitor observation in order to determine the patterns of use and the rate of certain depreciative behaviors. This thesis also addresses the physical impacts to the cliffs from recreation use. Resource impact assessments were conducted to augment and 
contextualize the direct observation data. To that end, the following research questions are addressed in this thesis:

1. What are the overall patterns of cliff use at the New River Gorge National River (NERI) by location and activity (climbing, hiking, others)?

1a. Which NERI visitors were engaged in what types of depreciative behaviors (hiking off trail, littering, etc.)?

1b. Is there a difference between user groups in terms of frequency and types of depreciative behaviors?

2. What is the nature and extent of the negative impacts to the cliff resource?

2a. What are the locations and severity of disturbance at cliff recreation sites?

3. By combining resource impact assessment data with visitor observation data, can we provide useful management recommendations that will help mitigate visitor impacts? 


\section{Chapter 2 Literature Review}

\section{Introduction}

Despite the sensitive nature of cliff areas and the increase in popularity of cliff activities such as climbing, surprisingly few studies like this have been done before. Wood, Lawson, and Marion (2006) recently conducted a similar cliff study in the Shenandoah National Park (SNP). This thesis could be thought of as an application of the methods used in the previous study to another cliff area. Although the cliff areas at NERI are larger than those at SNP by orders of magnitude, the previous study is a good starting point and was used as a rough model for this thesis. Other studies have focused on cliff impacts, cliff users, social trails, and visitor observation. However, as far as this author can tell, no other studies like this have been completed (except for the study mentioned above and another similar ongoing study in the Potomac Gorge). The following literature review discusses existing literature on cliff impacts, cliff users, social trails, and visitor observation.

\section{Recent Cliff Use Studies}

As mentioned above, the study completed by Wood et al. (2006) is the main starting point for this thesis, and will be referred to often. That study addressed two aspects of cliff use: visitor behavior and resource impacts. First, researchers dressed as visitors unobtrusively observed visitors at a specific cliff site. Researchers recorded people at one time (PAOT), length of stay, type of visitor (hiker, climber, backpacker), and whether these visitors engaged in certain depreciative behaviors (stepping off trail, trampling vegetation, ropes across the trail, etc.). The observations were conducted for a total of 14 days, two 
shifts per day, with both weekend and weekday sampling. Observers were able to stay more or less stationary in their observations due to the small physical extent of the study area. The second aspect of the study involved measurement of resource impacts at the study site. Established trail and site evaluation guidelines/procedures were applied to cliff resources to measure resource impacts. This included the area of disturbance in square feet, the linear extent of user created trails, and an inventory of specific impacts (such as damage to trees).

By combining the visitor observation data with the resource impact measurement data, the authors were able to better understand which user groups were causing which impacts. Managers at SNP had assumed that climbers were to blame for the majority of impacts at the site, but the study pointed to day hikers as the primary cause. This conclusion is based on components from both aspects of the study (impact measurement and observation). The location of the impacts, when coupled with visitor observation data, helped establish which user group(s) were causing them. Simple percentages (i.e. 50\%) were used to indicate the proportion of impacts by zone (cliff top, cliff base, etc.). T-tests were used to compare weekend vs. weekday usage among the three user groups (hiker, backpacker, climber). Then, a one-way ANOVA was conducted to determine if there was a significant difference between the three groups in terms of length of stay, trampling behavior, and trampled vegetation by zone. Again, day hikers were the cause for the majority of the impacts, mostly due to their sheer numbers. The data showed that there was a significant difference between the impacts of different user groups, and climbers were not responsible for a majority of the impacts as had been assumed. 
Although the study by Wood et al. (2006) is an excellent starting point for this thesis, there are two main limitations that should be addressed. First and foremost, this study is limited because there is not a large body of literature to expand upon. Second and more importantly, the particulars of the cliff site at SNP might make it difficult to apply these methods to other areas. For example, the relatively small cliff area at SNP allowed for very detailed measurements and observation from 2 fixed points. Other cliff systems with much greater extent (such as NERI) make this method very difficult for any comprehensive survey from a practical standpoint. Therefore, the methods laid out below were modified from the methods the study by Wood et al. (2006) to address the vast area of the cliff resources at NERI, while attempting to be as comprehensive as possible.

In addition to the study mentioned above, there is an ongoing study of cliff usage at the Potomac Gorge (near Washington, DC). That study has not been published yet, but a preliminary report is available from the USGS (Marion, 2007). The study consists of trail assessments (both official and social trails), and assessments of the informal overlook areas and named rock climbing routes along the cliff top and cliff base areas. The trail assessment was done according to a condition class rating system (I-IV), as well as a point sampling of tread conditions at 300 foot interval. A handheld GPS mapping unit was used to map the extent of the trail network, and to mark areas impacted by recreational activity (overlooks and climbing routes). In addition to the resource impact measurement and assessment, different management approaches to reducing hiking off trail were tested by collecting direct visitor observations. Visitors were unobtrusively observed from hidden, fixed locations. The management actions tested included trailhead signs, blazing, formal trails to vistas, signs at informal trailheads, and others tactics. 
Human Impacts on the Cliff Ecosystem

Several studies have been conducted on cliff ecosystems, especially the flora. These studies have certain limitations (site particulars and confounding variables) but generally indicate that the cliff ecosystem is particularly sensitive to human impacts such as trampling, scraping lichens, or other disturbance. Nuzzo (1995) studied an endemic cliff ecosystem plant species (Cliff Goldenrod) throughout dolomite cliffs in northwest Illinois. Transects were established on both climbed and unclimbed cliffs, and on different parts of the cliff. The density, size, and flower production (inflorescence) was measured in each transect. Using statistical methods, climbed and unclimbed areas were compared, and climbed sites showed higher rates of damage to Cliff Goldenrod plants. Similar damage was found on sites that had not been climbed heavily, suggesting that only a light use is required to cause a negative impact. Additionally, the age structure of the Cliff Goldenrod was different on climbed and unclimbed cliffs based on the size of various plant structures. Cliff Goldenrod was also found to prefer the cliff top area to other areas, and the cliffs studied had relatively little use on those areas, since climbing mostly occurs at the cliff base and cliff face. The study also suggests that this species grows back quickly once the activity ceases.

McMillan and Larson (2002) studied plant communities on climbed and unclimbed cliffs on the Niagara Escarpment in Ontario, Canada. They found significantly lower vascular plant density and cover in climbed areas, as well as a major reduction in bryophyte cover on climbed cliff faces. Lichen cover was similar across climbed and unclimbed cliff faces, but the species composition was different in favor of more resistant species. Also, climbed areas had a higher percentage of alien species, suggesting that 
human disturbance altered the species composition and allowed non-native species to take hold. Most trails in the area were not close enough to the cliff edge to disturb that area, but the authors acknowledge that hikers going off the trail may explain some of the impact to unclimbed cliff top areas.

Walker, Parisher, Smith, Whitlock, Karmar, Matthes, and Moorefield (2004) conducted a study in the Obed River Gorge in Tennessee. Transects were established on climbed and unclimbed cliff face, edge, or talus in order to compare the number and types of plants and the human impacts. Statistical methods were used to compare the variables of species richness and human disturbance on climbed and unclimbed cliffs. The cliff ecosystem was found to be sensitive to disturbance, but the cause of the disturbance could not be determined, as there was no statistically significant difference between climbed and unclimbed cliff areas. Many confounding variables (such as the slope/overhang of cliff areas) made it difficult to conclusively determine the causes of vegetation disturbance. Interestingly, the cliff edge area was found to have the most unique plant community, and was highly sensitive to human disturbance. The Obed River Gorge has a "no top-out" policy for climbers, which the author suggests might explain the lack of disturbance at the cliff edge.

The literature on cliff resource impacts suggests that human impacts caused by recreational use have a detrimental effect on the already sensitive plant communities associated with cliffs (McMillan \& Larson, 2002; Nuzzo, 1995; Walker et al., 2004). Cliffs have special biological significance given their limited spatial extent, and unique plant and animal communities. In addition to having biological significance, cliffs have a social significance as well. Humans seem to have an innate attraction to cliffs. In many cultures, 
cliffs are associated with sacred locations and occasions. Today, recreation and other important human activities are growing in popularity, increasing the potential strain on the cliff ecosystem (Larson et al., 2005).

\section{Cliff Users}

Another relevant strand of literature focuses on the cliff users (specifically climbers), their attitudes towards the cliff resource, and their management preferences. These studies used mostly survey instruments to determine the self-reported behavior and beliefs of climbers. Additionally, they all fit into existing literature on social carrying capacity, a concept with a long history in the study of outdoor recreation. As Manning and O’Dell (1997) note, social carrying capacity involves both social and biophysical elements. The social elements are often established normatively, from surveys of users, to determine the baseline standards of quality that should be adopted. Measureable indicators are then selected to track these standards over time. The surveys summarized below represent attempts to understand the baseline preferences of climbers, both nationally and at NERI.

Schuster, Thompson, and Hammitt (2001) collected 400 survey responses from 13 climbing locations throughout the United States. The survey asked questions about type of climber-eg., traditional (trad) or sport, demographic information (gender, etc.), ability level, and various attitudes toward management actions. Statistical methods were used to analyze the responses by type of climber and experience level. Climbers' attitudes toward management did differ between trad and sport climbers. Particularly, sport climbers had different attitudes (less positive) toward management of the use of bolts than trad climbers, who had a more positive attitude towards bolt management. This might be 
explained by the main distinction between the two types of climbing: the use of bolts in sport climbing and the management issues that accompany bolt use. All groups of climbers expressed reservations about management actions, and felt that managers did not sufficiently understand climbing.

Borrie and Harding (2002) studied the effectiveness of certain messages on rock climber behavior at climbing sites in Bitterroot Valley, Montana. The effectiveness of 3 different messages was tested by comparing survey responses across the 3 treatments. The survey asked climbers about their attitudes towards their own behavior and the behavior of others with respect to certain low impact behaviors. These behaviors included off trail hiking, bolt placing, and disturbance of cultural sites. The results indicated that trailhead messages might not be effective as there was no difference between any of the treatment messages and the control messages. Additionally, differences between climbers might explain differences in attitudes toward low impact practices. More experienced climbers (experience both with the sport and at the specific site) had less reservations about placing new bolts than less experienced climbers. Climbers who learned indoors had different attitudes than those who did not, and sport climbers had different attitudes than trad climbers. The perceived lack of a defined official trail affected the results as well because the respondents did not know whether they were hiking off trail, so they could not self-report that behavior accurately. Most of the respondents did note the network of social trails as a problem. Overall, the study suggests that different communication strategies may work best with different subgroups of climbers. It also suggests that climbers across the board are concerned with certain resource impacts. 
Gilbertson (2002) surveyed climbers at Shovel Point, Minnesota to determine their attitudes toward management actions. The area had several negative resource impact issues that managers hoped to address through site hardening, re-vegetation, and other actions such as cliff closure. The climbers surveyed indicated a good deal of positive support for management actions designed to address the negative resource impacts. Climbers also had faith in other climbers abiding by any changes or rules. Certain management actions were perceived negatively as impacting the wilderness quality of the experience (i.e. site hardening). The study also found that climbers generally respected revegetated areas (as indicated by the lack of trampling of new growth).

Monz (2009) studied the management attitudes of climbers in the Adirondack Park. The research focused on climbers' attitudes towards social conditions, resource impacts, and certain management practices. Sixty-six climbers were surveyed. The results indicate that the vast majority of climbers surveyed found resource impacts such as damage to trees and trampled vegetation to be offensive. Impacts such as bare soil, social trails, and erosion were found to be slightly less offensive (but still offensive). Climbers generally cited crowding as a major negative social condition, but noise was less of a negative condition. Additionally, most climbers were opposed to or neutral towards management of climbing areas (i.e. regulation of bolts).

Attarian (1998) surveyed NERI climbers, and found similar results to the studies above regarding climbers' attitudes towards resource impacts. The surveyed climbers agreed with leave no trace practices, and disagreed with negative practices such as chiseling handholds and removing vegetation from the cliff area. Additionally, most (70\%) of the respondents identified themselves as advanced or expert level climbers. Over $20 \%$ 
of the respondents reported helping out at a climbing area maintenance project, and nearly all thought climbers should help maintain climbing areas. Nearly a third were members of the Access Fund, and over 80\% read two popular climbing magazines (Rock and Ice, and Climbing). Respondents were also concerned by large groups of climbers, favoring limitations on group size.

Ramthun (2002) also surveyed climbers at NERI and found somewhat similar results. Most (over 75\%) respondents reported they were advanced or intermediate climbers. Similar to the study by Monz (2009), climbers did not find impacts such noise to be a major problem, and crowding as a slightly more important concern. The study was limited by severe weather (in July) and the closure of several climbing areas and trails. Therefore, the results might not be indicative of climbers at NERI over an entire season, and across all of the climbing areas. The results do match up with other studies on climbers in general and at NERI particularly.

Overall, these cliff user studies indicate that climbers are generally not in favor of direct management actions, but are concerned about certain resource impacts (Borrie \& Harding, 2002; Gilbertson, 2002; Monz, 2009). Additionally, different subgroups of climbers might have different attitudes towards resource impacts and management actions (Borrie \& Harding, 2002; Schuster, 2001). Climbers at NERI seemed to share similar attitudes towards negative impacts (Attarian, 1998; Ramthun, 2002). These studies are survey based, so they are inherently dependent on the responses of the cliff users. Direct observation studies, like the study by Wood et al. (2006) and this thesis, have the potential to improve future surveys of cliff users, and to give managers better insight into what is 
actually happening. This insight should help managers make better decisions in an environment that might be skeptical of management actions in general.

\section{Resource Impact Measurements}

In addition to direct observation of cliff users, which will be addressed below, this thesis addressed the resource impacts present at NERI. The cliff base, cliff top, and social trails were examined to determine presence and extent of certain negative resource impacts. Campsite evaluation methods can be applied to cliff base and cliff top impacts (Wood et al. 2006). There is also a great deal of literature on trail assessment, and these methods are easily applied to social trails. The term social trail, as used in this thesis, means any trail that is not created and/or managed by the NPS. Social trails are problematic because they are sometimes located in sensitive areas (causing disturbance to plants and animals), and are not built according to proper trail construction guidelines. Therefore, they are often prone to erosion and other further negative impacts. They also tend to proliferate over time, and this can lead to negative impacts on the scenic qualities of the area (Marion et al., 2006).

Cole, Watson, Hall, and Spildie (1997) compared several high-use wilderness areas in terms of recreation impacts such as social trails and campsite impacts. Researchers inventoried social trails and campsites to determine the number and extent of each. The area of disturbance was measured for both social trails and campsites, measured in square meters. Both the number of disturbed sites and the condition of the sites were considered, and an aggregate figure of impacted area was calculated. Specific impacts, such as damage 
to trees and fire scars, were also counted. Similar calculations could be useful to NERI managers to establish a baseline for future measurements.

Marion and Leung (2001) compared the point sampling and problem assessment techniques for trail assessments. Point sampling is simply picking a fixed distance interval, and taking detailed measurements of trail conditions at that interval. Problem assessment is also fairly simple, involving the selection of specific indicators (such as excessive grade, soil erosion, wet soil, excessive width, root exposure, secondary treads, and running water on trail), and then taking an inventory of those indicators when encountered along the specific trail. Obviously, the problem assessment is more subjective, and requires certain indicators to be well defined prior to any assessment. Nonetheless, each method highlights different information, making both methods potentially useful.

Nepal and Nepal (2004) studied trails near Mt. Everest. The ecological impacts to trails were surveyed both quantitatively and qualitatively. The qualitative portion included a class rating system (I-IV) according to damage level. Trail depth and other measurements were taken at fixed intervals to determine the soil lost due to erosion. The methods used are similar to the study cited above (Marion and Leung, 2001) and combine both a problem assessment and point sampling methodology.

In another study, Marion, Leung, and Nepal (2006) compared two methods for monitoring trails, especially social trails. Aerial photographs were analyzed in one method, and that was compared with "boots on the ground" GPS mapping. The GPS mapping method consists of a researcher walking the length of each trail with a handheld GPS unit, thereby measuring the length of the trails and mapping their locations. The aerial photographic method was found to be nearly as accurate as the GPS mapping method to 
address social trails. The authors also used a condition class rating system from I-IV based on the level of damage (light to severe) that would apply to social trail ratings. The condition classes start with class I, which is a "lightly damaged trail" and continue to class IV, a "severely damaged trail". The criteria are primarily qualitative, and are established before the assessment is completed. See the table (Table 1) below for the condition classes used by Marion et al. (2006). While the study found that aerial photography could be useful to map social trails more efficiently, the method only applies to areas where tree cover is not a factor. Unfortunately, tree cover is a factor at NERI, and the GPS method appeared to be the best fit for this thesis.

Manning, Jacobi, and Marion (2006) also studied techniques for monitoring resource impacts and other indicators at Acadia National Park. Part of the study included social trail mapping and assessment. A GPS survey was conducted to map the linear extent of the social trail network. Then, point sampling and problem assessment methods were integrated. Trail width and tread depth were measured at fixed intervals (from a randomized starting point). Specific indicators (problems defined previously) were also counted and the extents of these problems were measured. Additionally, specific fixed areas where certain problems were present were logged in the GPS and photographed for subsequent studies as a basis of comparison. A condition class rating system was used to categorize the social trails based on both the qualitative and quantitative data.

These studies on social trails and resource impacts describe specific methods for resource impact measurement. The study by Wood et al. (2006) also laid out specific methods that will be addressed in chapter 3 of this thesis. There appears to be a consensus that both problem assessment and point sampling methods provide useful data that can be 
Class I Lightly damaged trail, Either on or a combination of several impact features present. Trail width is $<5 \mathrm{ft}$; no more than three treads apparent; low to moderate potential for trail expansion; some muddy spots may be present; incision is $<0.5 \mathrm{ft}$; some exposed and loose soil may be present on the trial surface. Overall, a trail under this classification is stable and odes not require any maintenance as long as the conditions do not deteriorate further.

Class II Moderately damaged trail. Trail segments clearly show deteriorating conditions. Either a single impact feature with significant damage, or a combination of more than two impact features is present: trail is wider than $5 \mathrm{ft}$; incision between 0.5 and $1.0 \mathrm{ft}$ (incision of $1.5 \mathrm{ft}$ in the absence of any other features will satisfy the condition itself); more than three treads are present; muddiness and running water on trail; trail is displaced; and soil is unconsolidated. The degree and magnitude of trail damage is significant enough to prescribe some management actions.

Class III Highly damaged trail. This is a potential hotspot, showing either one type of impact feature or a combination of several features. Both the magnitude and the extent of damage are significant. Basic impact features include trail width, multiple treads and incision. Usually these are present in combined forms, for example, trail braiding leading to excessive width. In certain cases, trail width is less but several treads are present, some of which are deeply incised ( $>1.5 \mathrm{ft}$ ). Frequently exposed bedrock and roots are present in addition to other impact features. A trail affected by landslides or localized slope failures also qualifies as a highly damaged trail.

Class IV Severely damaged trail or "hotspot." Either a single criterion or a combination of several impact features qualifies this category. The basic parameters are trail width, multiple treads, and trail incision, and are significantly damaged in extent and magnitude compared with Class III. Other impact features being satisfactory, if the basic parameters show heavy damage, it is considered as severely damaged. A trail under this classification exhibits excessive width ( $>10 \mathrm{ft}$ ), multiple treads $(>5)$, and incision $>1.5 \mathrm{ft}$. It may also exhibit signs of downhill sliding. Soil on the trail surface is unconsolidated, and no organic layer is present; exposed bedrock is frequent; trailside is highly eroded; root exposure is excessive; trail is very muddy requiring circumvention; trail outslope is $>10 \%$. Overall, a trail under this classification requires urgent repair, without which land degradation is inevitable in the near future. Damage is likely to spread out both vertically (depth) as well as horizontally.

Note. Modified from Marion, Leung, \& Nepal (2006)

integrated to provide a useful understanding of social trail networks (Manning et al., 2006;

Marion et al., 2006; Wood et al., 2006). GPS mapping is also a common component of

social trail assessment due to the unofficial nature of these trails, especially when

combined with standard trail assessment techniques (Manning et al, 2006; Marion, et al.

2006). Additionally, the study by Wood et al. (2006) adapted established campsite

assessment methods to measure impacts at climbing sites. 


\section{Visitor Observation}

Direct participant observation appears to be desirable in certain circumstances, but limited time and staffing present a logistical problem for researchers (Alessa, Bennett, \& Kliskey, 2003; Borrie \& Harding, 2002). This might account for the lack of previous literature in the subject. However, there are a few behavioral studies that have been conducted that provide a basic background on visitor observation.

Alessa et al. (2003) used unobtrusive, direct visitor observation to study the effect of visitor knowledge on the rate of depreciative behavior at Pacific Rim National Park in Canada. A team of volunteers surveyed visitors on their ecological knowledge before they entered a sensitive area. Another team unobtrusively followed them and noted instances of certain depreciative behaviors (stepping on sensitive vegetation, etc.). A third team of researchers then interviewed the visitors as they went back to the visitor center. The visitors thought there were two teams of researchers (not three) and were not aware they were being observed. Interestingly, the researchers found that the most knowledgeable visitors engaged in the most depreciative behaviors.

Bradford and McIntyre (2007) used trail counters and closed circuit video monitoring to test the effectiveness of sign placement and message choice on social trail use behavior at St. Lawrence Island National Park in Canada. The video monitoring methodology is an attractive option, but this thesis used a direct observation method. The sheer extent of NERI made it difficult and too costly to monitor enough area with video. This study did use trail counters as a backup for the video data, with the counters placed at 
the main entry point and on selected social trails. The two figures were then compared to determine a rate of social trail usage.

Hughes, Ham, and Brown (2009) used direct observation to test compliance with park regulations regarding dog leash compliance and bird feeding behavior at two parks in Australia. Visitors were unobtrusively observed, and categorized into groups of compliers or non-compliers. Then, specific questionnaires were given to members of both groups based on their observed behaviors. The purpose was to test the effectiveness of certain types of messages on rule compliance, but it is an example of a study where direct unobtrusive visitor observation was used. The authors noted that even the presence of an unobtrusive observer might have had a subtle effect on the behavior of the visitors. Observers reported that some visitors kept their dogs on a leash as long as they were within sight of the researchers. Thus, the authors speculate that the very presence of another person within view might decrease the rate of depreciative behaviors. Interestingly, the study also found that frequent visitors might be the most resistant to persuasion, perhaps due to certain ingrained bad habits. 
Chapter 3 Methods

\section{Introduction}

As noted before, there are very few studies similar to this proposed thesis. The model for this thesis is the study completed by Wood et al. (2006). The methods used in that study involved two main aspects: visitor observation and resource impact measurement. This thesis used similar but adjusted methods for visitor observation and resource impact methods due to the differences in the study areas. The methods employed can be broken down into two categories: visitor observation and resource impact measurement. As noted earlier, the following research questions are addressed in this thesis:

1. What are the overall patterns of cliff use at the New River Gorge National River (NERI) by location and activity (climbing, hiking, others)?

1a. Which NERI visitors were engaged in what types of depreciative behaviors (hiking off trail, littering, etc.)?

$1 \mathrm{~b}$. Is there a difference between user groups in terms of frequency and types of depreciative behaviors?

2. What is the nature and extent of the negative impacts to the cliff resource?

2a. What are the locations and severity of cliff disturbance at cliff recreation sites?

3. By combining resource impact measurement data with visitor observation data, can we provide useful management recommendations that will help mitigate visitor impacts? 


\section{Visitor Observation}

Visitor observation methods were employed in order to answer research questions $1,1 \mathrm{a}$, and $1 \mathrm{~b}$. Specifically, this thesis sought to identify the overall patterns of cliff use at NERI by location and activity (climbing, hiking, others). It also focused on which NERI visitors are engaged in what types of depreciative behaviors (hiking off trail, littering, etc.). To that end, direct unobtrusive visitor observation was employed at four sites over 30 days from June to September of 2010. Days were selected using a simple online random number generator (dice), with weekends and weekdays weighted separately to ensure more weekend days were sampled. Some observation days were impractical due to severe weather or other issues, and when possible the day was rescheduled for the next suitable day. The four sites selected were Diamond Point Overlook, Ram's Head Overlook/Rappel Point, Junkyard Wall, and Endless Wall between Honeymooners and Fern Creek ladders (Figure 2). The observations at Diamond Point Overlook and Ram's Head Overlook employed a stationary observation position. The observer sat in a single location and quietly took notes on the participants in the area. The observations at Junkyard Wall and the area of Endless Wall employed a roving observation scheme. The observer simply did a large circuit repeatedly each observation day. Observations were conducted from approximately $10 \mathrm{am}$ to $5 \mathrm{pm}$. On some days this was cut short due to weather, or lack of groups to observe. A focus group meeting with experienced local climbers was held in March 2010 to help determine the best location for observations. Additionally, the latest guidebook was consulted to assist in observation site selection. The sites were picked because they represented areas with noticeable resource impacts and were known to be popular destinations for day hikers and climbers. 


\section{Map of Observation Locations New River Gorge National River (NERI) Cliff Use Study}
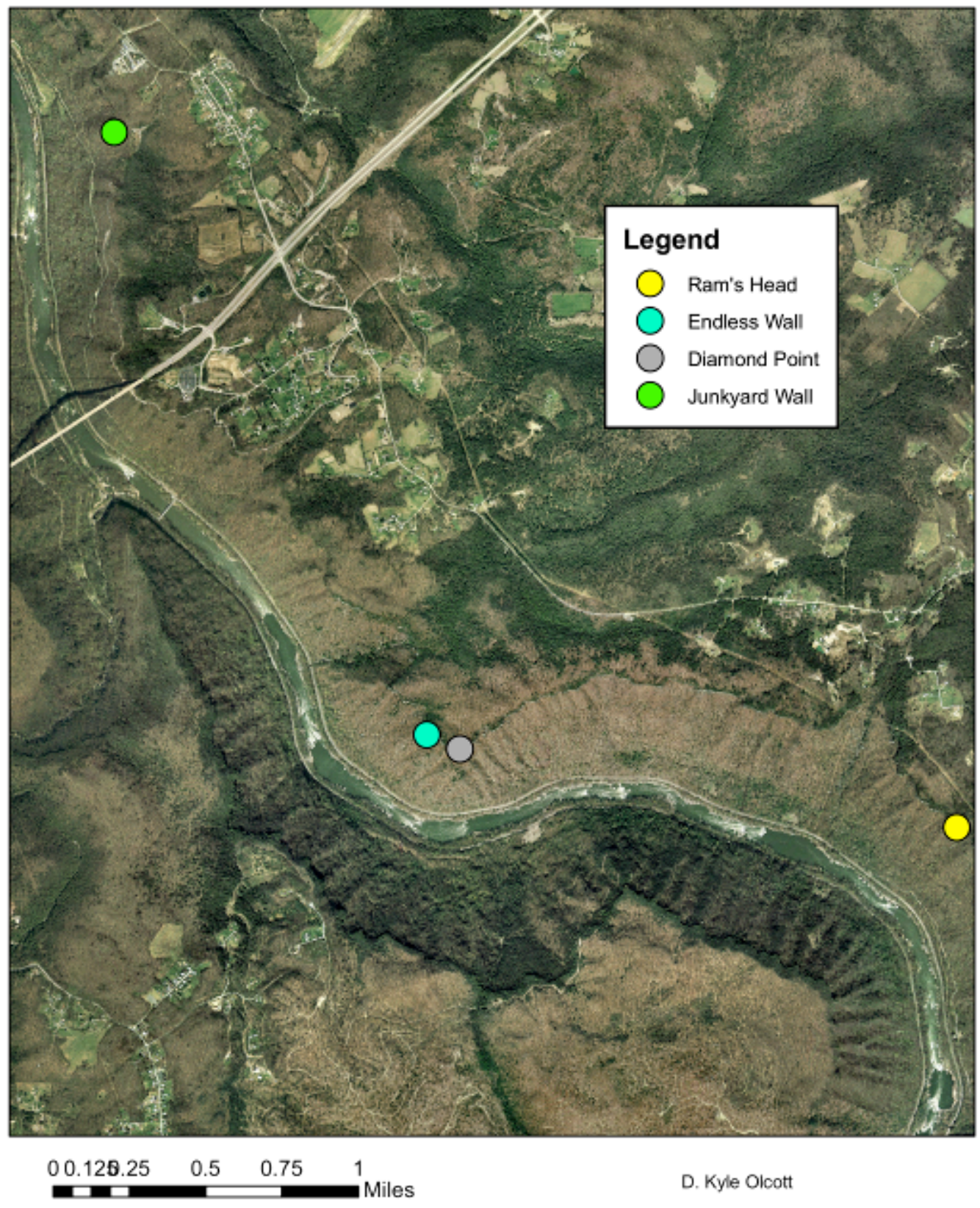

D. Kyle Olcott

Figure 2: Map of observation locations 
The observations were conducted without the visitors' knowledge, by this author dressed as a typical visitor (i.e. casually, no uniform). Like the study by Wood et al. (2006), the information collected by observation consisted of group size, type of user, specific depreciative behaviors (i.e. stepping off trail, scraping lichens off the cliff face, vegetation trampling, etc.), length of stay, and other informal qualitative observations. The results were then analyzed using the R statistical platform to determine if any significant differences exist between user group in terms of depreciative behaviors and cliff usage in general. Research question 1 was answered by analysis of all the observation data, 1a was answered by analysis of the data to determine the overall rate of depreciative behaviors, and $1 \mathrm{~b}$ was answered by comparing the rate of depreciative behaviors by type of user.

\section{Resource Impact Measurement}

Because of time and personnel constraints, this thesis employed a rapid assessment, condition class based rating for all areas of impact at the cliff top and base-called nodes of use. A total of 444 nodes of use were mapped in ESRI ArcPad using a Magellan Mobile Mapper GPS unit theoretically capable of sub-meter accuracy. Other points of interest, such as top anchor points, ladders, signs, and latrines were mapped as well. All data were loaded into ESRI ArcMap GIS software for analysis and processing.

As in the study by Wood et al. (2006), the recreation sites (nodes of use) were generally identified as areas of disturbed vegetation (i.e. bare soil or diminished leaf litter). The following condition class categories were developed by Wood, Lawson, and Marion (2006): 


\section{Condition Class Description}

Class 0 Site barely distinguishable; no or minimal disturbance of vegetation and /or organic litter. Often an old site that has not seen recent use.

Class 1 Site barely distinguishable; slight loss of vegetation cover and /or minimal disturbance of organic litter.

Class 2 Site obvious; vegetation cover lost and/or organic litter pulverized in primary use areas.

Class 3 Vegetation cover lost and/or organic litter pulverized on much of the site, some bare soil exposed in primary use areas.

Class 4 Nearly complete or total loss of vegetation cover and organic litter, bare soil widespread

Class 5 Soil erosion obvious, as indicated by exposed tree roots and rocks and/or gullying.

Note: modified from Wood, K. T. (2006)

This thesis employed the above condition class rating system, with the omission of Class 0 (because these sites would not be of interest and impossible to locate). The location of each node was logged on the GPS unit, the node was photographed, the condition class was noted, the cliff position (top or base) was noted, and the presence of a bolted route was noted. ESRI ArcPad software has the ability to create a data dictionary that allows for custom drop down menus that speed data entry and processing. This feature was used to create a data dictionary that allowed the attributes of each node to be directly recorded at the same time as the position of each node. Another data dictionary and ArcPad shape file category was created to record the other points of interest noted above (top anchors, ladders, etc.). 
Social Trails

In order to attempt answer research question 2a, a partial social trail inventory and assessment was completed. A condition class rating (Table 1) was employed on social trails, and official trails were mapped. This portion of the project became problematic because park officials were unable to provide assistance in identifying which trails were actually maintained (official). It was discovered that some trails at NERI are indeed maintained by the NPS, but many more are not. The park does not appear to have a trail plan or a list of trails by VERP zone. Park cooperation would have been very beneficial, but was elusive within the somewhat narrow timeframe of this research. The trail assessment methods laid out in Chapter 2 of this thesis will be passed along to park managers for future use once they have a sufficient idea of their trail planning objectives.

Additionally, there are many places where no clear trail exists, primarily at the base of the cliffs, but there are clearly several routes over loose rocks and boulders that visitors use to access various climbing routes. Because of these issues, it was decidedly difficult for this researcher to do a proper survey of social trails. Despite that, a good deal of social trail data was collected, mainly near the four visitor observation sites. This thesis, however, will not include the results of this portion because analysis of this data is ongoing due to the issues noted above.

\section{Painting an Overall Picture}

In order to answer research question 3, the data from both the resource impact and visitor observation portions will be combined and used to inform management 
recommendations. The hope is that, like the study by Wood et al. (2006), the information provided to managers will be useful to them in formulating policies to lessen the impacts to the cliff resource. In that study, the managers assumed climbers were to blame for a majority of the impacts, but the data indicated that day hikers were a more pressing management concern. Either way, real data should be important to managers, whether it confirms or disconfirms their previously held assumptions. The following chapters will discuss the results and Chapter 5 will discuss the potential implications of this thesis. 
Chapter 4 Results

The results put forth below are the result of several months of solo work by this author. The widely dispersed nature of the cliff use at NERI posed many unforeseen logistical challenges and ultimately resulted in curtailing the initial goals of this thesis. Some of the data that was collected is not addressed in this thesis, but will be part of the final report to NERI managers. The first section of this chapter outlines some of the important information gleaned from the visitor observation study and the second section discusses the resource impact assessment. Chapter 5 addresses the third research question by providing several management suggestions based on the data.

\section{Visitor Observation}

The results of the visitor observation portion of this study demonstrate some of the salient differences between hikers and climbers, the two main cliff user groups at NERI. Observations were conducted at four sites, over 30 total days, with 84 total groups observed. The observation sites were Diamond Point Overlook (8 total observation days), Ram's Head Rappel Point/Overlook (8 total observation days), Junkyard Wall Climbing Area (8 total observation days), Endless Wall Climbing Area (6 total observation days). The observations at Diamond Point Overlook and Ram's Head Rappel were from a fixed location (stationary observer), and the observations at Junkyard Wall and Endless wall employed a roving observer (Table 3). Data collected included length of stay, number and type of depreciative behaviors, user type (and subtypes of climbers), and group size. Climbers had a mean length of stay of 163.3 minutes (Figure 3), a mean group size of 3.42, and averaged 
1.05 depreciative behaviors per group. Hikers had a mean length of stay of 20.9 minutes (see Figure 4), a mean group size of 3.14, and averaged 0.92 depreciative behaviors per group.

Table 3 Visitor Observation Descriptive Data Summary

\begin{tabular}{llccc} 
Site & Fixed/Roving & $\begin{array}{c}\text { Number of } \\
\text { Observation } \\
\text { Days }\end{array}$ & \multicolumn{2}{c}{$\begin{array}{c}\text { Number of Groups } \\
\text { Observed (and percent of } \\
\text { total by user type) } \\
\text { Climber }\end{array}$} \\
Hiker
\end{tabular}

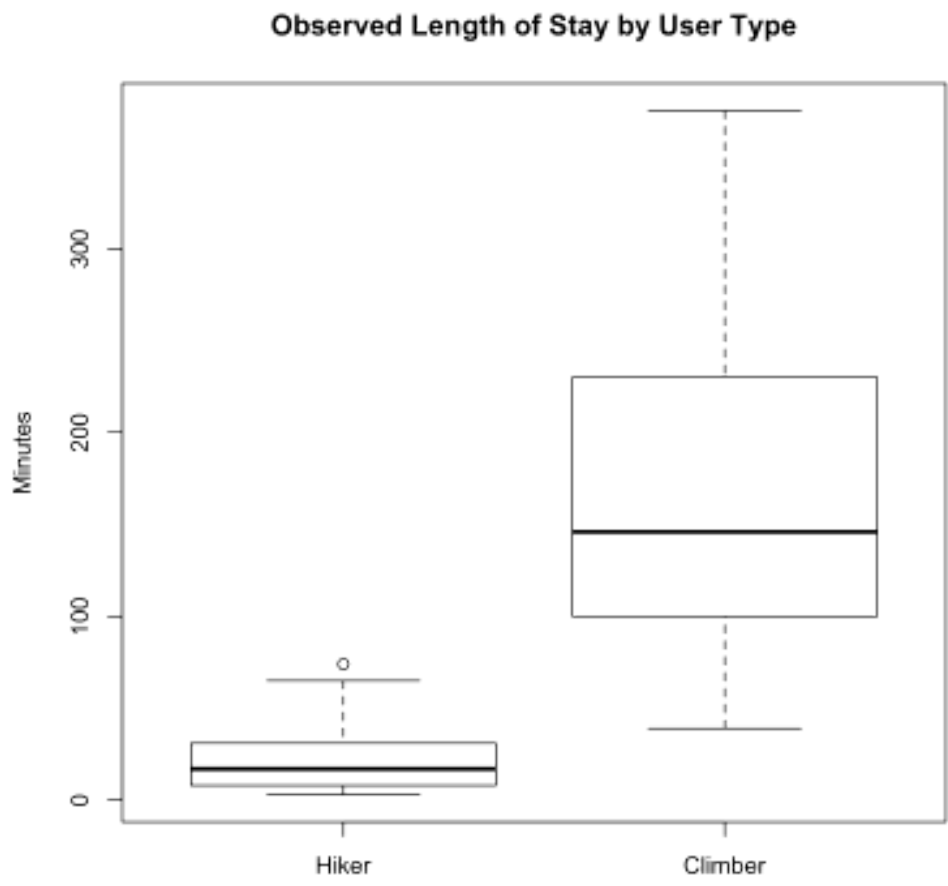

Figure 3: Boxplot comparing length of stay by user type 


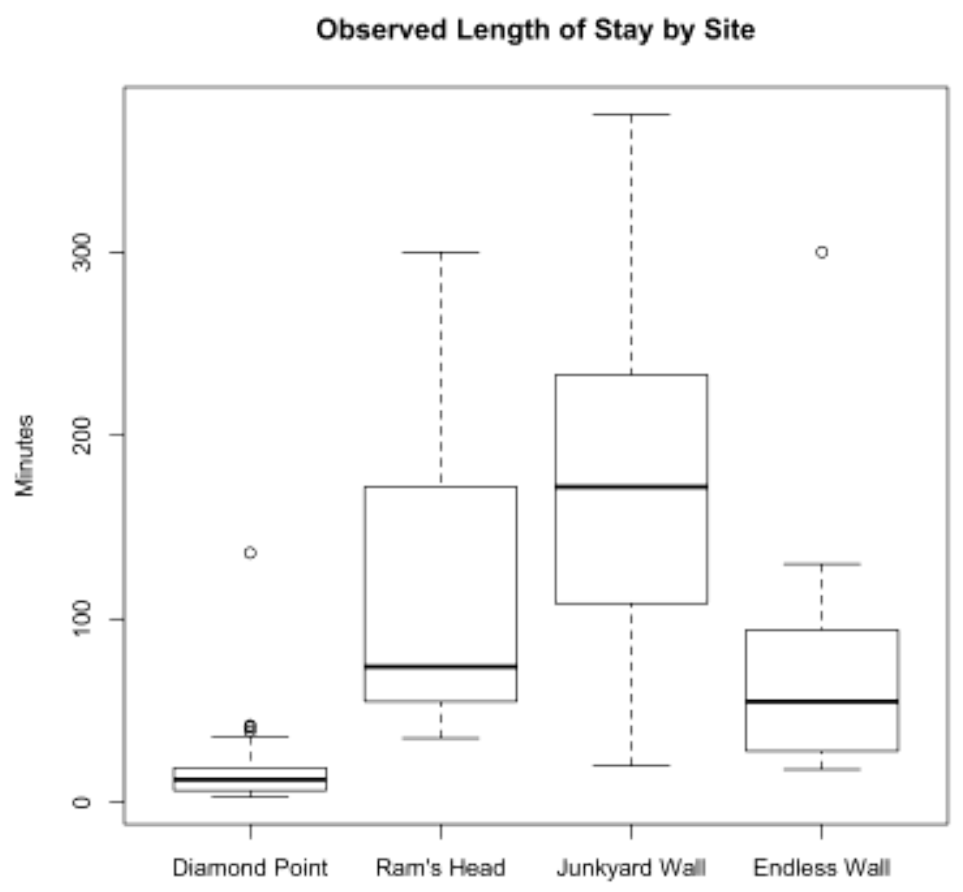

Figure 4: Boxplot comparing length of stay by observation location

An ANOVA was performed using the R statistical platform (R Development Core Team, 2011) to determine if any significant differences existed between user groups in terms of length of stay and number of depreciative behaviors per person. Based on this test, no significant differences were found in the number of depreciative behaviors per person between user types, observation sites, length of stay, or group size (Table 4). There was a significant difference between hikers and climbers in length of stay (see Table 5 and Figure 3; $p<0.001$ ), and a significant difference in length of stay between sites (Table 5 and Figure 4; $p<0.001$ ). 
Table 4 Analysis of Variance for Depreciative Behaviors Per Person

\begin{tabular}{rccccc}
\hline Source & $d f$ & $S S$ & $M S$ & $F$ & $p$ \\
\hline Site & 3 & 0.20 & 0.06 & 0.22 & 0.88 \\
User Type & 1 & 0.19 & 0.19 & 0.62 & 0.43 \\
Length of Stay & 1 & 0.21 & 0.21 & 0.69 & 0.40 \\
Group Size & 1 & 0.0001 & 0.0013 & 0.0004 & 0.98 \\
Residuals & 66 & 20.68 & 0.31 & & \\
\hline
\end{tabular}

Table 5 Analysis of Variance for Length of Stay

\begin{tabular}{rccccc}
\hline Source & $d f$ & $S S$ & $M S$ & $F$ & $p$ \\
\hline Site & 3 & 337253 & 112418 & 27.13 & $<0.001^{*}$ \\
User Type & 1 & 74867 & 74876 & 18.07 & $<0.001^{*}$ \\
$\begin{array}{r}\text { Depreciative } \\
\text { Behaviors Per }\end{array}$ & 1 & 6374 & 6374 & 1.53 & 0.21 \\
$\begin{array}{r}\text { Person } \\
\text { Group Size }\end{array}$ & 1 & 6975 & 6975 & 1.68 & 0.19 \\
$\begin{array}{r}\text { Residuals } \\
\text { Reside }\end{array}$ & 66 & 273432 & 4143 & &
\end{tabular}

The types of observed depreciative behaviors did vary between hikers and climbers (Table 6) and among the different types of climbers (Table 7). Top-rope climbers were more frequently observed anchoring to a tree, and this behavior was observed repeatedly even when fixed anchors were nearby (Figure 5). Several groups utilized both fixed anchors and tree(s) simultaneously, perhaps using the tree(s) as backup. Top-rope climbers and rappelling groups were responsible for most of the observed depreciative behaviors among climbers (Table 7). These two subgroups accounted for the vast majority 
of climber groups observed, as opposed to trad and sport climbers who accounted for a small percentage of climber groups observed and observed depreciative behaviors (Figure 6). It should also be noted that day hikers were observed on three occasions causing intentional damage to trees more along the lines of vandalism (Figure 7). Additionally, only one group of day hikers (non-climbers) was observed at the cliff base. Day hikers were primarily attracted to overlook points at the cliff top. Hikers were also observed hiking off trail more often than climbers (Table 6). Climbers were observed at both the cliff top and cliff base positions, mainly frequenting the cliff top to set anchors and spending the majority of their time at the cliff base.

Table 6 Observed Depreciative Behaviors by User Type

\begin{tabular}{rcc} 
& \multicolumn{2}{c}{ User Type } \\
Depreciative Behavior & Climbers & Hikers \\
Anchor to Tree & 18 & 0 \\
Non-official Trail Use & 10 & 5 \\
Top-out & 5 & 0 \\
Trampling Vegetation & 3 & 19 \\
Off Trail Hiking & 3 & 12 \\
Tree Damage & 0 & 3 \\
\hline Total & 39 & 39 \\
\hline
\end{tabular}

Table 7 Observed Depreciative Behaviors by Type of Climber

\begin{tabular}{rcccc}
\hline \multirow{2}{*}{$\begin{array}{c}\text { Type of Climber } \\
\text { Depreciative Behavior }\end{array}$} & Trad & $\begin{array}{c}\text { Sport } \\
\text { Top- }\end{array}$ & Rappel \\
Anchor to Tree & 0 & 0 & 13 & 7 \\
Non-official Trail Use & 1 & 0 & 9 & 0 \\
Top-out & 3 & 1 & 1 & 0 \\
Trampling Vegetation & 0 & 0 & 3 & 2 \\
Off Trail Hiking & 0 & 0 & 3 & 0 \\
Tree Damage & 0 & 0 & 0 & 0 \\
\hline Total & 4 & 1 & 29 & 9 \\
\hline Number of Groups Observed & 9 & 2 & 24 & 4 \\
\hline
\end{tabular}




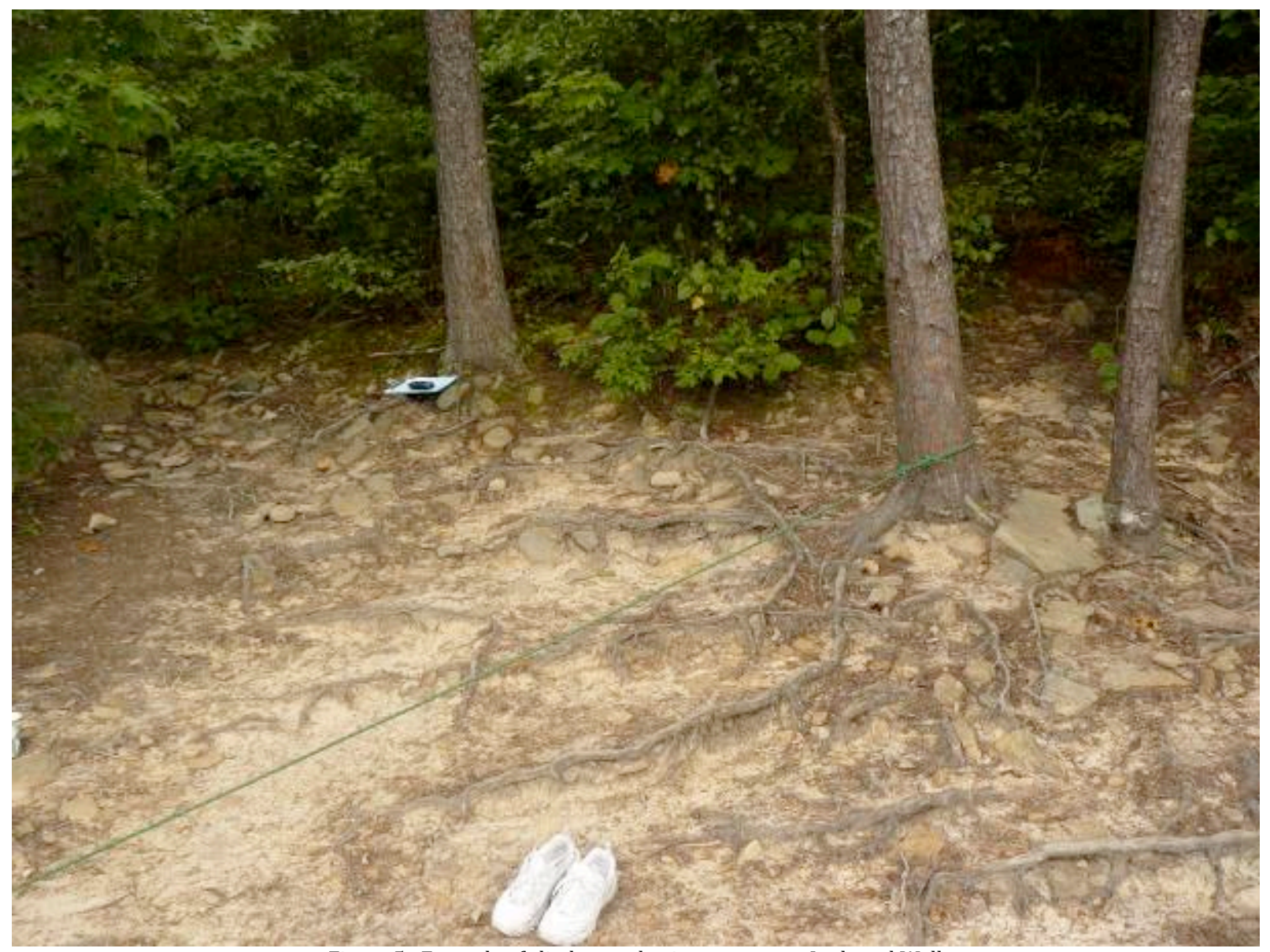

Figure 5: Example of climber anchoring to a tree at Junkyard Wall

\section{Number of Observed Groups by Type of Climber}

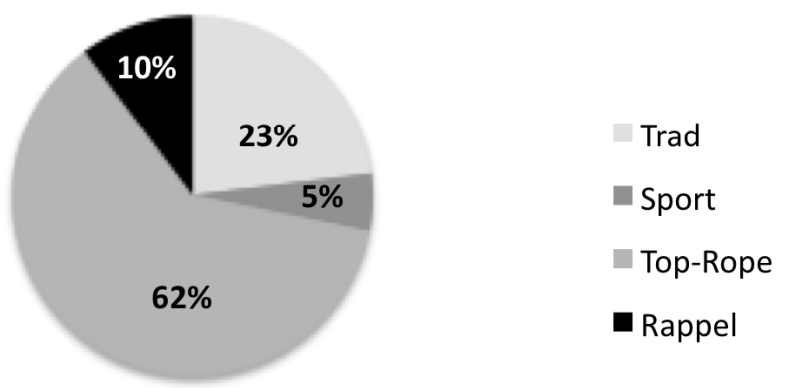

Number of Observed Depreciative Behaviors by Type of Climber

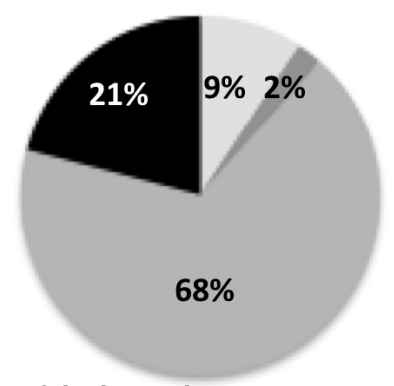

Figure 6: Pie charts representing number of groups observed by type of climber and number of depreciative behaviors observed by type of climber 


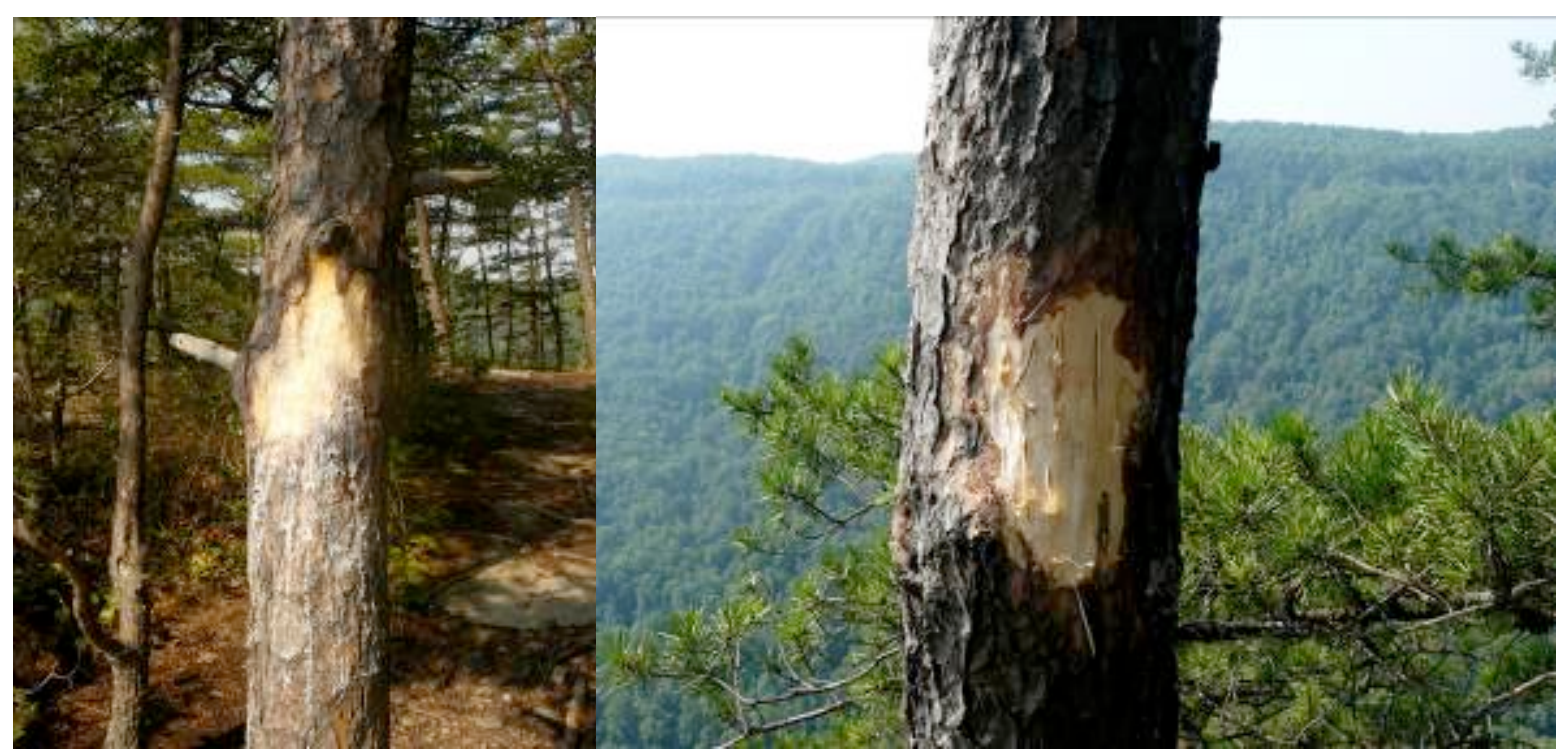

Figure 7: Photos of visitor caused tree damage at Diamond Point Overlook, the observer was present when the damage in the photo on the right was caused

It should also be noted that over the course of the study this observer did not notice any (or minimal, restricted to the parking lots and roads) NPS law enforcement presence in any of the cliff areas. Cliff use at NERI is centered on the cliffs but widely dispersed along several miles of river. Access to some areas is physically difficult and often treacherous. Thus, due to staffing limitations, any potential rules or regulations regarding cliff use will need to have a high rate of voluntary compliance. This will be discussed more in the next chapter.

In summary, the visitor observation results indicate there was no significant difference between climbers and hikers in the number of observed depreciative behaviors per person (Table 4). There was a significant difference in length of stay between climbers and hikers, and by observation location (Table 5, Figures 3 and 4). The differences in 
length of stay by observation location are obviously due to the breakdown of observed groups by user type, but serve to further confirm the difference in length of stay. Although climbers were observed to stay much longer than hikers, as noted, no significant differences were found in number of depreciative behaviors or group size. Additionally, the types of depreciative behaviors were different between climbers and hikers, and among climbers by type of climber. Most of the observed climber groups were top-rope climbing or rappelling. These two subgroups were often observed using trees as anchors, in several cases in conjunction with a fixed bolt anchor.

\section{Resource Impact Assessment}

The results below come from the resource impact assessment conducted at each climbed area at NERI. A total of 444 areas of impact were mapped and a quick assessment of the condition of the site was made. The presence or absence of a bolted route was also noted, and photos of each node were taken. Fixed top anchors (Figure 8) were mapped separately.

Figures 9 and 10 show two different views of the nodes of use that were mapped in this study. Figure 9 includes the top anchor points, which are clearly clustered in some of the more popular areas, such as Bridge Buttress, Junkyard Wall, Endless Wall, and Beauty Mountain. Figure 10 identifies the nodes of use by climbing area (taken from the guidebook). These areas are primarily distinguished by the access points used to reach to cliffs, and are mainly located on the right side of the river if one faces downstream. The New River Gorge Bridge (a famous state landmark) is located nearby, as well as the NERI's main visitor center. 


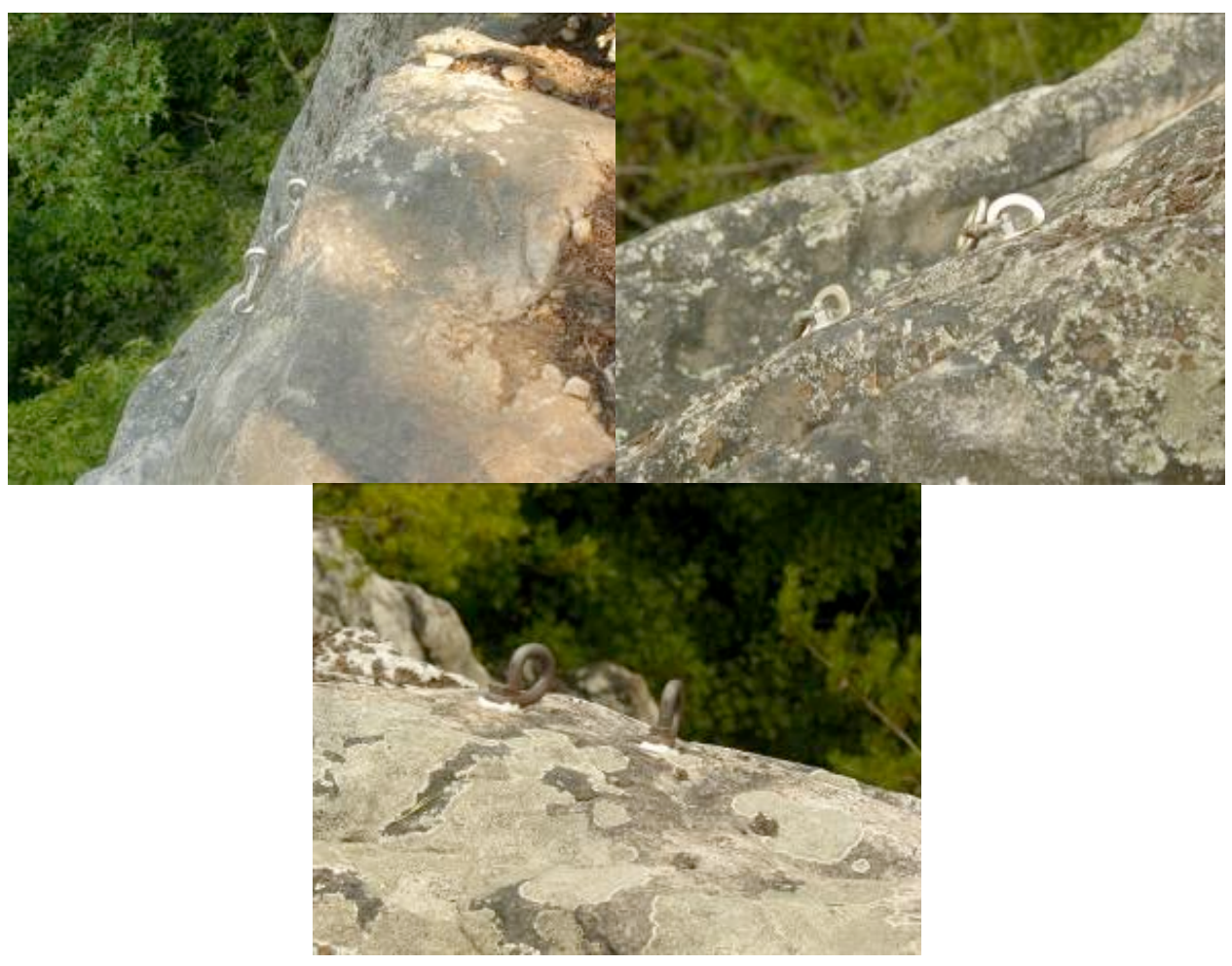

Figure 8: Examples of fixed top anchors at Endless Wall

Using ESRI ArcMap "select by location" tool, it was possible to separate the nodes of use within specified distances of top anchor points. Using Pearson's Chi-Squared test for homogeneity, it was possible to determine if each sub-population of interest had a significantly different distribution from the overall distribution (Figure 11). Skewing towards the higher condition classes is an indication that the level of visitor impact is greater. Tests were run on the nodes within $5,10,20,30,50$, and 100 meters from top bolt anchors, and also comparing nodes with bolted routes to nodes without bolted routes (Table 8). The results of these tests indicate that there is a significant $(p<0.05)$ difference between nodes 5, 10, 20, and 30 meters from a top bolt anchor and the total population of nodes. There is also a significant $(p<0.05)$ difference between nodes with bolted routes and nodes without bolted routes. As you can see by the distributions (Figure 12), the 
nodes closer to the top anchors are all skewed toward the condition classes that indicate a higher level of impact. Looking at the graph of the distribution, the nodes with bolted routes are also skewed towards the higher condition classes (Figure 13).

\section{Map of Recorded Nodes of Use and Top Anchors New River Gorge National River (NERI) Cliff Use Study}
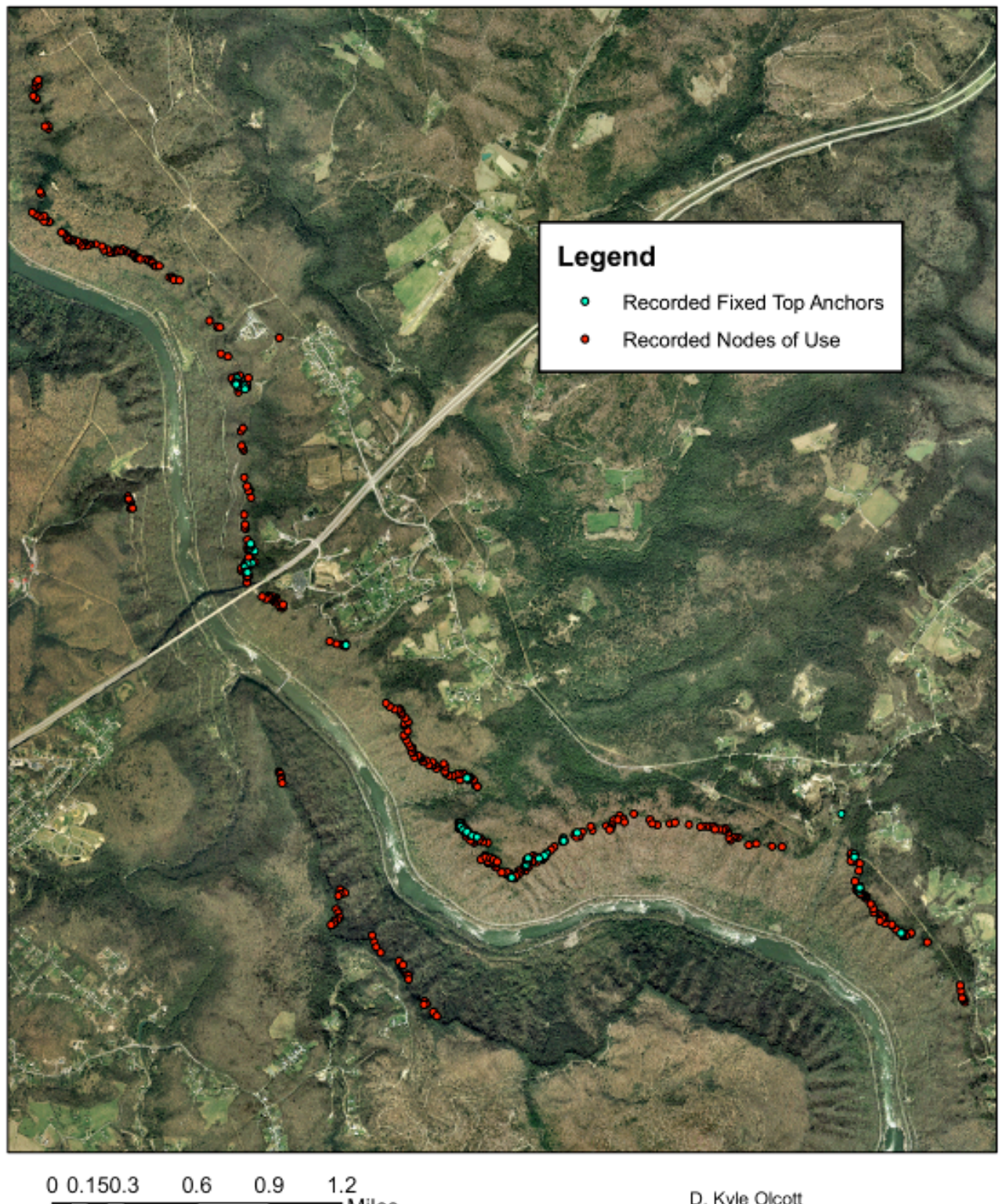

Miles

D. Kyle Olcott

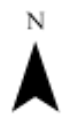

Figure 9: Map of all nodes of use and fixed top anchors 


\section{Map of Recorded Nodes of Use by Climbing Area New River Gorge National River (NERI) Cliff Use Study}
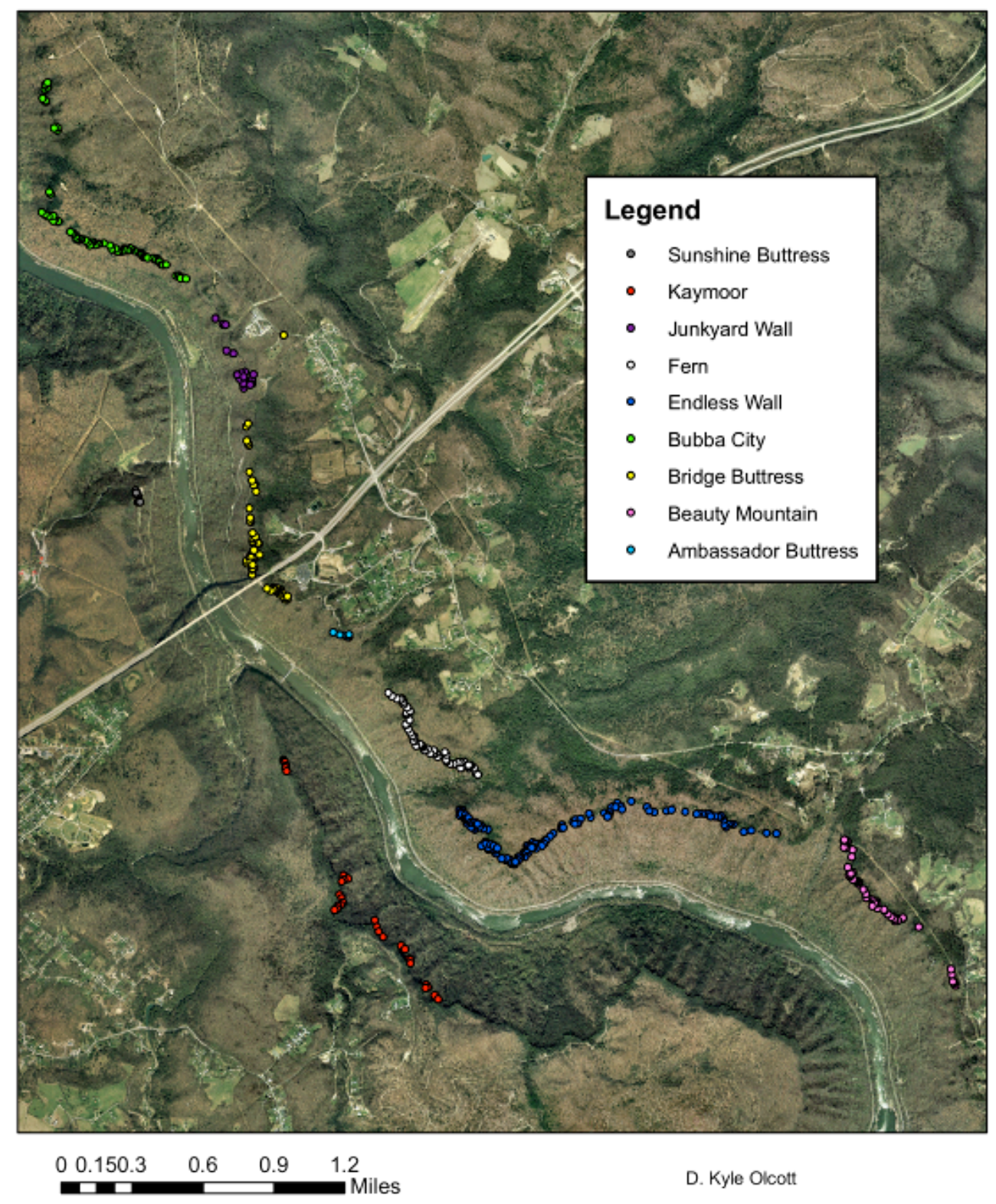

D. Kyle Olcott

Figure 10: Map of nodes of use by climbing area 


\section{Condition Class of All Nodes}
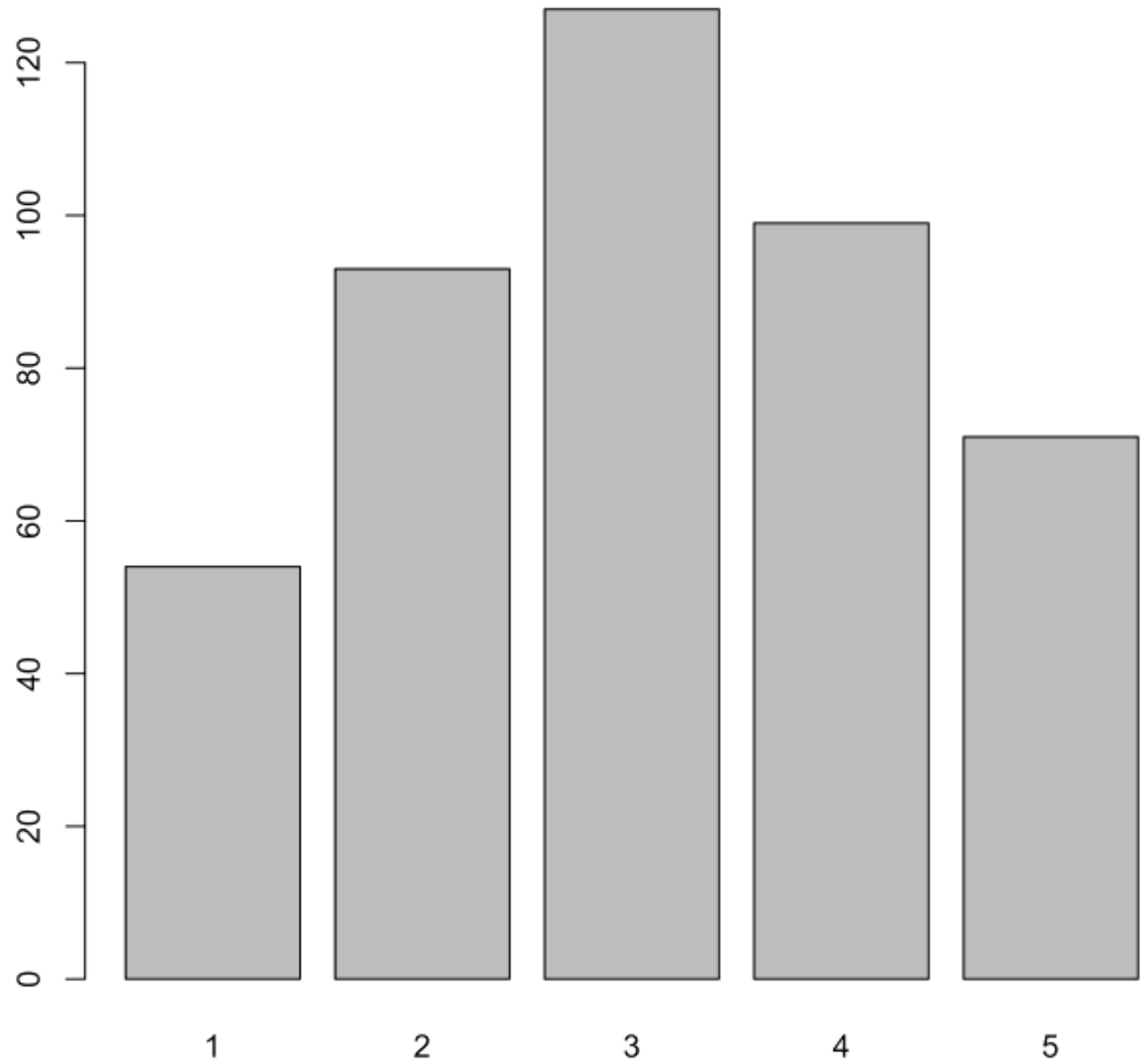

Condition Class

Figure 11: Condition class distribution of all nodes 

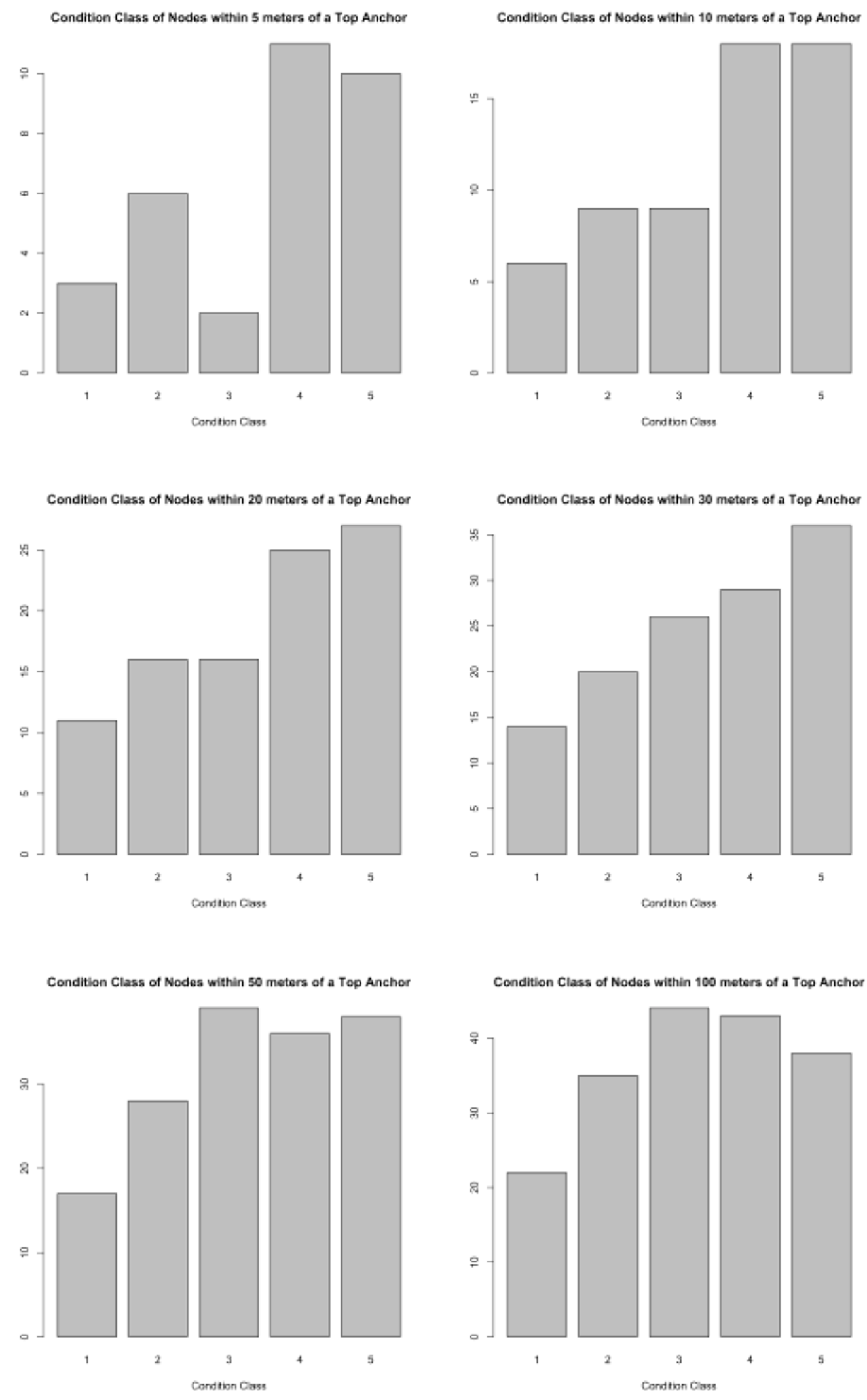

Figure 12: Condition class distributions for nodes within specified distances of top anchor point 


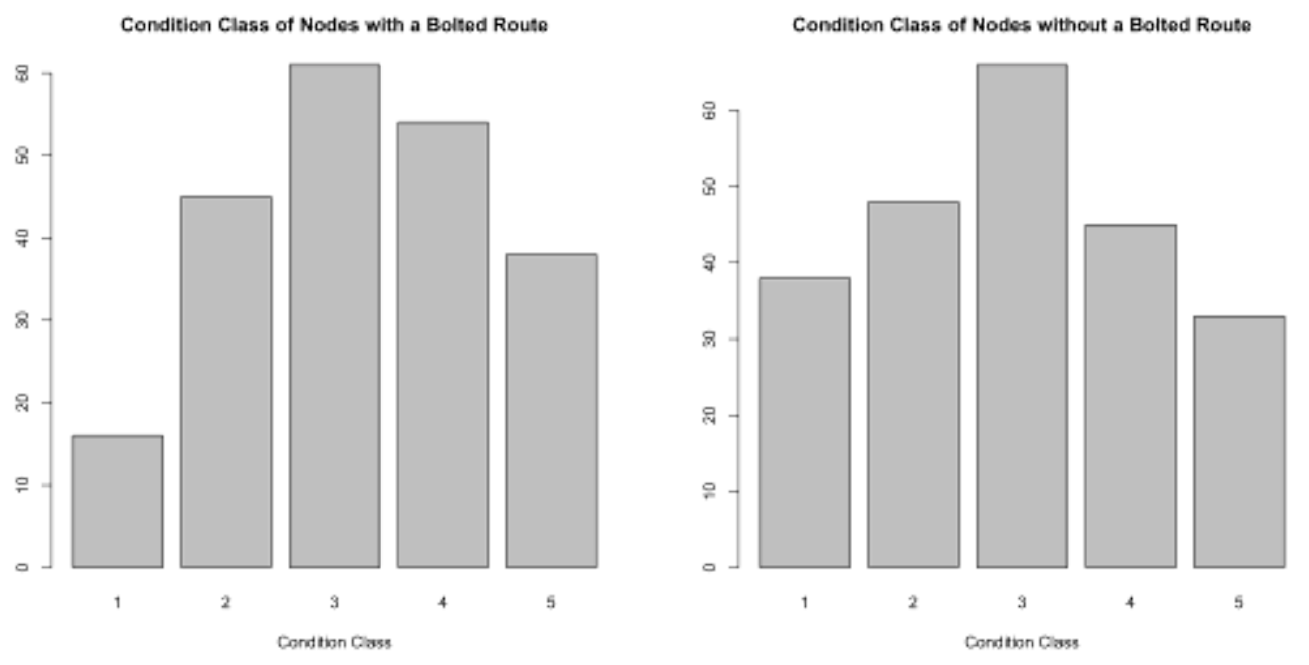

Figure 13: Condition class distributions for nodes with and without bolted routes

Table 8 Chi-Square Test of Homogeneity of Node Condition Class Distribution

\begin{tabular}{|c|c|c|c|c|c|c|c|c|}
\hline & \multicolumn{5}{|c|}{ Condition Class } & \multirow{3}{*}{$\begin{array}{c}\chi^{2} \\
\mathrm{n} / \mathrm{a}\end{array}$} & \multirow{3}{*}{$\begin{array}{c}d f \\
\mathrm{n} / \mathrm{a}\end{array}$} & \multirow{3}{*}{$\begin{array}{c}p \\
\mathrm{n} / \mathrm{a}\end{array}$} \\
\hline & 1 & 2 & 3 & 4 & 5 & & & \\
\hline All Nodes & 54 & 93 & 127 & 99 & 71 & & & \\
\hline $\begin{array}{l}\text { Within } 5 \mathrm{~m} \text { of } \\
\text { top anchor }\end{array}$ & 3 & 6 & 2 & 11 & 10 & 11.73 & 4 & $0.019^{* *}$ \\
\hline $\begin{array}{l}\text { Within } 10 \mathrm{~m} \\
\text { of top anchor }\end{array}$ & 6 & 9 & 9 & 18 & 18 & 11.98 & 4 & $0.017^{* *}$ \\
\hline $\begin{array}{l}\text { Within } 20 \mathrm{~m} \\
\text { of top anchor }\end{array}$ & 11 & 16 & 16 & 25 & 27 & 11.95 & 4 & $0.017^{* *}$ \\
\hline $\begin{array}{l}\text { Within 30m } \\
\text { of top anchor }\end{array}$ & 14 & 20 & 26 & 29 & 36 & 12.03 & 4 & $0.017^{* *}$ \\
\hline $\begin{array}{l}\text { Within } 50 \mathrm{~m} \\
\text { of top anchor }\end{array}$ & 17 & 28 & 39 & 36 & 38 & 5.63 & 4 & 0.22 \\
\hline $\begin{array}{l}\text { Within } 100 \mathrm{~m} \\
\text { of top anchor }\end{array}$ & 22 & 35 & 44 & 43 & 37 & 2.98 & 4 & 0.56 \\
\hline $\begin{array}{l}\text { Bolted } \\
\text { Routes }\end{array}$ & 16 & 45 & 61 & 54 & 38 & $\mathrm{n} / \mathrm{a}$ & $\mathrm{n} / \mathrm{a}$ & $\mathrm{n} / \mathrm{a}$ \\
\hline $\begin{array}{c}\text { Non-Bolted } \\
\text { Routes }\end{array}$ & 38 & 48 & 66 & 45 & 33 & 9.86 & 4 & $0.042^{* *}$ \\
\hline
\end{tabular}

**Significant difference, $p<0.05$

Note: The condition class distribution of nodes with bolted routes was compared with the condition class distribution of nodes without bolted routes, all other categories (i.e. the condition class distribution of nodes within $\mathrm{x}$ meters of top anchor) were compared with the condition class distribution of all nodes 
To recap, the significant results obtained from the resource impact assessment of the cliff nodes of use indicate greater impacts nearest to fixed top anchor points and in sites with bolted routes. The overall population of nodes appears to have a rather normal looking distribution, so it is easy to see how the data are skewed in each of the above distributions (Figures 11-13). A distribution skewed towards higher condition class ratings indicates a higher level of impact. One can clearly see that the distribution of nodes closest to fixed top anchors is highly skewed towards the higher condition class ratings. The next chapter will address these results and the results of the visitor observations and some potential management implications stemming from the combination of both types of data. 


\section{Chapter 5 Discussion}

The mission of the National Park Service is, "to conserve the scenery...and to provide for the enjoyment of the same in such a manner and by such means as will leave them unimpaired for the enjoyment of future generations" (NPS Organic Act, 16 U.S.C.1.). This mission is, on its face, contradictory. How can you both allow use and enjoyment and protect the land for the future? Recreation ecology has show that even a small number of people can cause drastic damage to fragile ecosystems. Hardening every site is not feasible, nor is it always desirable. The easiest way to preserve the land would simply be to close it off from humans completely. Obviously, managers at NERI do not have this option because they are legally obligated to allow as much use as is sustainable. The question is what exactly is sustainable use? And, in order to allow for as much enjoyment as possible, what can managers actually do to lessen the impacts of recreation use? This is where empirical research comes in, using science to inform management decisions to fulfill the dual, and often conflicting, mission of the National Park Service. Some have argued that mitigating or preventing resource impacts is the moral thing to do, as Aldo Leopold writes in $A$ Sand County Almanac: "A thing is right when it tends to preserve the integrity, stability, and beauty of the biotic community. It is wrong when it tends otherwise" (p. 262).

This study, like many in the social sciences, was partially inductive. That is, the expected results were not known prior to the beginning of the fieldwork. Rather, the goal was to observe visitor behavior and assess site characteristics to help better understand the nature and extent of the visitor impacts at the cliffs in NERI. As time went on, it became clear that anchoring behavior and the physical location of top anchor points were 
important. Damage to the cliff top area is very noticeable in many areas of NERI. You can see a stark contrast between a heavily used top node such as Figure 14, and a nearby but less used top such as Figure 15.

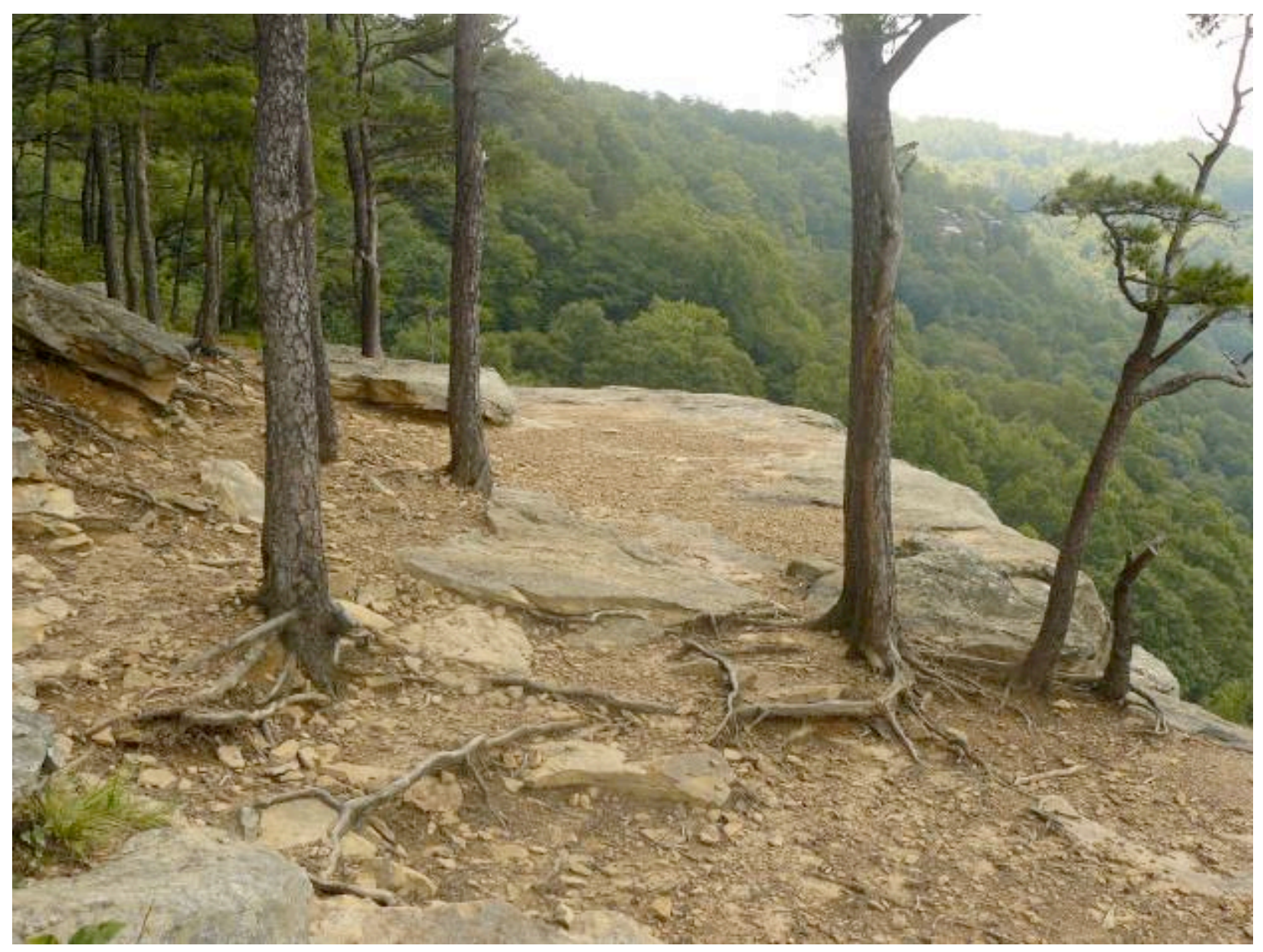

Figure 14: One view of the heavily impacted cliff top area at Ram's Head 


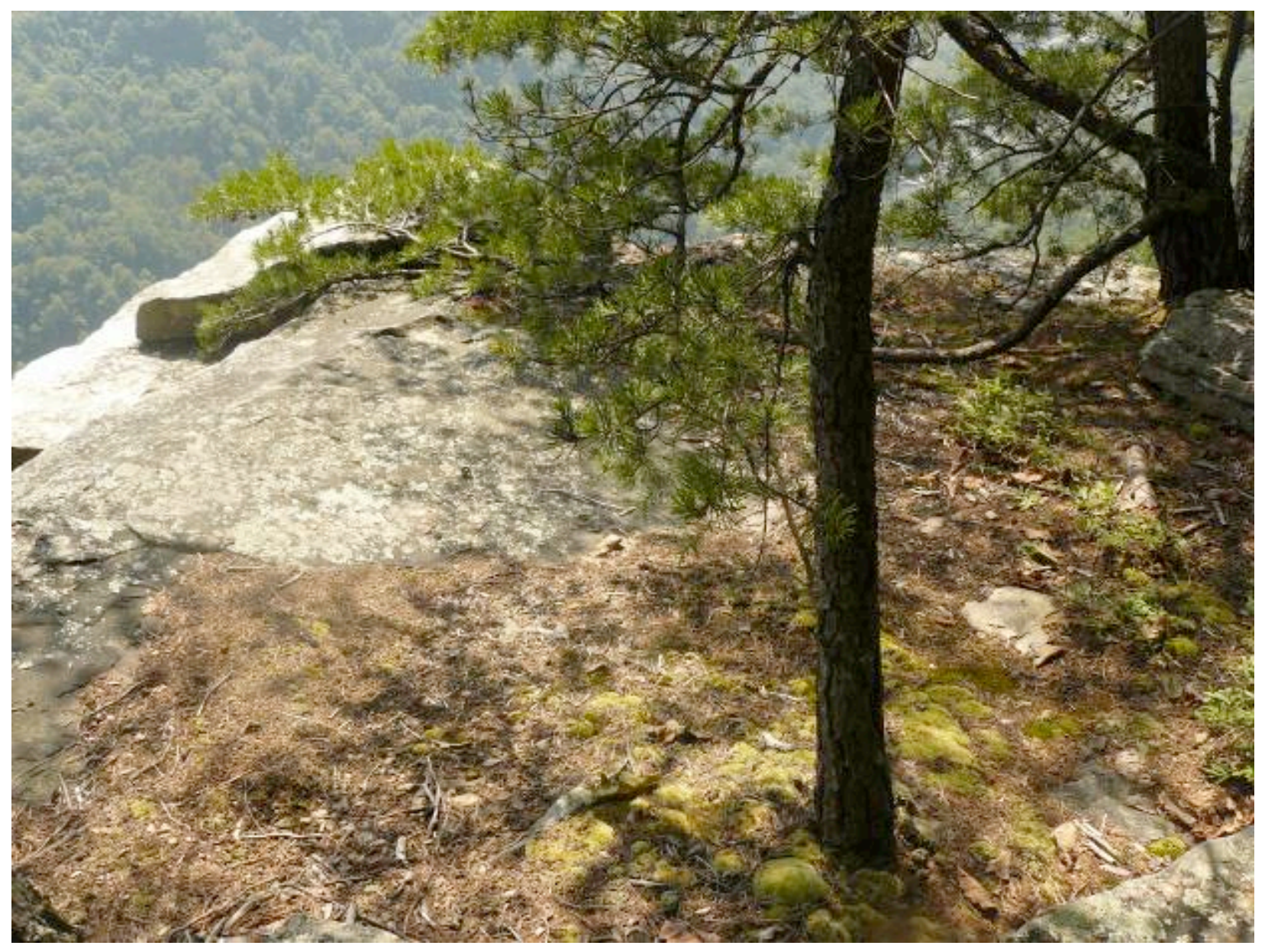

Figure 15: An example of a less impacted cliff top site, at Beauty Mountain just downstream from Ram's Head

The data put forth above does seem to indicate that a pressing concern for NERI managers is the better regulation of cliff top use, especially the placement of top anchors and the use of trees. Another item of concern is the placement of bolted routes used by sport climbers. The severity of impacts increase when fixed top anchor points are nearby, and this could be explained in two ways. First, the impacts are more severe because the presence of bolted routes attracts more use and therefore more impact. Or, second, the fixed bolted routes are mainly placed at already popular places with greater pre-existing impacts, maybe even in an attempt to lessen the future impacts or the use of trees as anchors. The answer is most likely some combination of the two, but this does not change 
the ultimate conclusion. Many top rope climbers were observed using trees as anchors in addition to the fixed top anchors. In climbing, it is a common and accepted practice to utilize a backup anchor as a safety measure. Anchors attract top rope climbers to the cliff top where they must set their anchors. Even if they do not use a tree they are still impacting the cliff top sites. Day hikers, seeking overlook points, then follow the social trails to these cliff top areas, causing even more impacts. Because of this, one solution is to restrict the use of trees as anchors, as well as the placement of any new top anchor points. Certain areas should be managed for top rope and rappelling use, in conjunction with a strict "no top out" policy for the remaining areas. Trails should, whenever possible, be rerouted away from the cliff edge, only going to fixed, well marked overlook points that might have to be hardened.

As stated above, the data indicates fixed top anchors should be restricted to designated top rope climbing areas, and a strict no top out policy should be adopted in other areas. This should be implemented in conjunction to a strict ban on anchoring to trees. Another NPS unit, the Obed Wild and Scenic River in Tennessee, has adopted a similar policy in their Climbing Management Plan (2002). This park unit implemented a moratorium on new bolt anchors of any type, and restricted rappelling to certain areas. Using trees as anchors was prohibited, as was removing vegetation cover to "clean" a climb. At NERI, the most recent Climbing Management Plan (2005) restricts the use of power drills, and imposes a series of approval processes for the placement of new routes. Although NERI is not managed as wilderness, the NPS has proposed new climbing management guidelines for wilderness sites, which are currently up for public comment. According to Section 7.2 of Director's Order \#41 (2011), the new guidelines state that 
climbers should use temporary equipment rather than fixed bolts or anchors, power drills are prohibited (used for bolting anchors), Leave No Trace principles are encouraged (including packing out human waste), fixed anchors may be necessary "but should be rare in wilderness", and park managers should directly regulate placement, replacement, and removal of new bolts. The proposal also says management should attempt to control or even reduce fixed anchors in wilderness areas, and states that bolted climbs are not in line with the goals of a wilderness. It appears the NPS recognizes, at least for wilderness areas, that fixed anchors and bolted routes can be problematic. Some of the areas at NERI, particularly those that are more remote and less used, could potentially be managed according to wilderness criteria mentioned above. At NERI, designated rappel and top rope areas would obviously be excluded from the wilderness management standards, and managed as sacrifice sites that are hardened against visitor impacts.

NERI is home to a strong community of recreationists, and a very active community of climbers who are already directly involved in the management of the routes and climbed areas. On several occasions, route cleaning, trail work, and bolt placement by NERI volunteers was observed during the course of this study. Engagement with these groups is essential given the goal of the NPS, which is to provide for use of the resource in a responsible way. As indicated above, any policy will need to have a high rate of voluntary compliance, due to the dispersed nature of the cliff resource and the low levels of management presence. NERI managers will surely prefer to have the support of the climbing community when implementing any policy change.

Siderelis and Attarian (2004) surveyed climbers at a state park in North Carolina by mail, to try and model the effects of proposed rules changes on the likelihood of the 
respondents desire to return in the future. The results indicated that proposed closures of climbing areas and proposed management attempts to lessen visitor impacts and restrict access significantly reduced the likelihood of future trips. This study shows one potential consequence of management actions designed to lessen impacts at cliff sites. Climbers may simply "vote with their feet" and utilize another area. This would definitely be an indication of dissatisfaction. NERI managers would be wise to implement any policy changes in the most delicate way possible, with the consultation and advice of the local climbing community. This is because, despite being skeptical of management actions, studies have shown that climbers do care about negative impacts at cliff sites, such as those depicted in Figure 16. Monz (2009) surveyed climbers in the Adirondacks and found they were concerned with negative impacts such as damage to trees, litter, erosion, and others. However, they were not in favor of management actions. Interestingly, climbers did not seem to mind bare soil at climbing sites, in some cases viewing that as beneficial.

Jones, Hollenhorst, and Hammitt (2004) looked at the aesthetic preferences of cliff visitors regarding the use of bolts using a photo-questionnaire. The results suggested that as climbers become more experienced (specialized) they become more desensitized to the visual impact of fixed bolts. The results also suggest that the level of specialization and environmental awareness of the individual affects the aesthetic perception of bolts. The authors recommend education targeting human impacts to address what they view as a socially constructed phenomenon. At NERI, managers should take into account the preferences of cliff users (especially climbers) when making policies. Bolted route placement primarily affects climbers, because (with the exception of one observed hiker group) only climbers venture to the base of the cliff. Hikers preferred the cliff top, and 
therefore would not see any bolted anchors except for the fixed top anchors. Thus, it would be best to work with the climbing community and come up with acceptable bolted route management policies. This would be especially important, should NERI managers choose to manage some of the cliff areas according to proposed NPS wilderness guidelines mentioned above.
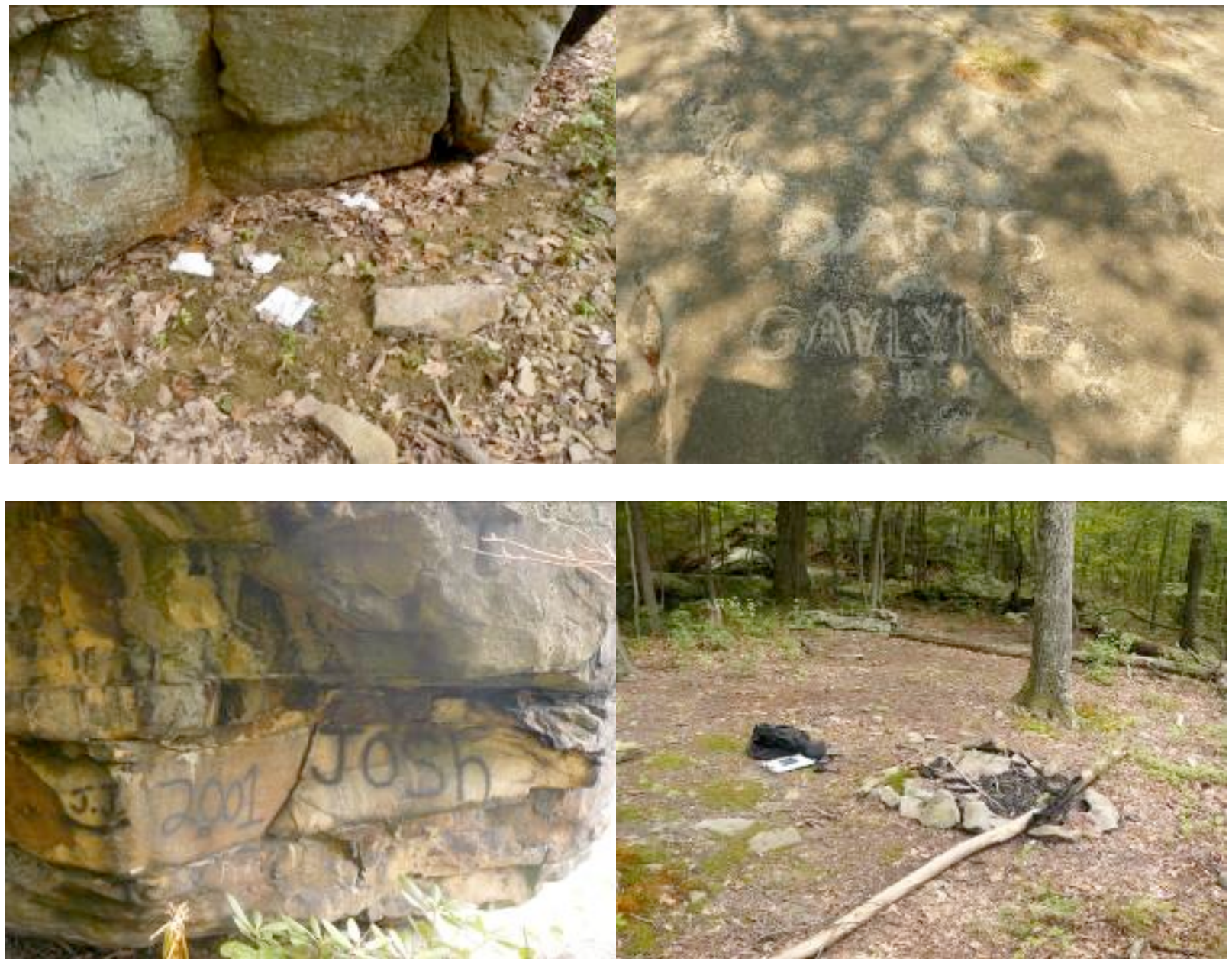

Figure 16: Examples of impacts, clockwise from top left: human waste at Junkyard Wall, names carved in the cliff at Beauty Mountain, graffiti at Endless Wall, illegal campsite near Junkyard Wall

The study by Monz (2009) points to skepticism climbers have towards management presence. Georgiade (2005) compared survey results from three climbing areas, including the New River Gorge. The results indicated that climbers in the state managed area (the 
other two were federally managed) had a better impression of park management and rangers because they were in contact with them more often, building rapport. The author noted that the state managed climbing area is much more compact than the two federally managed areas, which probably accounts for the increased management presence due to logistical feasibility. The study suggests that park managers would be wise to interact with the climbers more often to build a better relationship and boost the opinion climbers have of management. This would have the added side benefits of more enforcement of rules and regulations, and a more positive working relationship with local climbers, who can then take on an even greater role as stewards of the area.

Although climbers and hikers were found to engage in the depreciative behaviors noted above at approximately the same rate, simply standing and walking around a small area over a period of time will cause impacts such as soil compaction and erosion. Since climbers were found to have a significantly higher length of stay, they are also potentially causing more impacts concentrated at the top and base of their chosen climbing routes. Hikers would go from place to place, staying only a few minutes and moving on, while climbers would stay all day and possibly move a few times during a climbing session. Hikers were observed at some locations in fairly large numbers, but climbers were observed in large numbers at other locations. The study by Wood et al. (2006) found similar differences in length of stay between climbers and hikers. In contrast to this study, they found day hikers to be the primary cause of the negative impacts to the particular cliff area in SNP. This was important because managers assumed climbers were to blame. At NERI, both user groups appear to be similar in terms of the number, but not type, of their depreciative behaviors, but climbers' length of stay is much longer. At NERI, no group is 
more or less of a concern, but they are different. Both groups need to be addressed with different management strategies and interpretive products, addressing the specific depreciative behaviors each user group is engaged in. Since climbers are often part of a larger, organized, and actively engaged community, the management strategies employed will obviously be different than those used for hikers.

To summarize, NERI managers must accommodate as much use as is sustainable, and work within both social and physical realms. Any regulation restricting climbing or bolting in any way has the potential for a negative reaction from the climbing community. In light of new NPS Wilderness guidelines, as well as the policies used at other nearby park units, combined with the results from this study, it is recommended that: 1) the strict banning of anchoring to trees at all but designated "sacrifice" areas, 2) a strict "no top out policy", and 3) limits are placed on new bolted routes and top anchor points and possible removal of existing ones. The location of the approved routes and sacrifice sites should be determined based on the needs of the local climbing community, including local guide services. These recommendations should be implemented in conjunction with an education campaign designed to target specific visitor groups (or subgroups). Additionally, NERI law enforcement should try to step up patrols by "climbing rangers" in order to foster an environment of mutual respect and cooperation, rather than one of suspicion and opposition. This will have the added benefit of enforcing any new proposed rules; perhaps with a softer hand at first as area ethics change. Changing the habits and preferences of such experienced, specialized users will not be quick or easy (Hughes et al., 2009), but must occur if managers hope to avoid unsustainable degradation of the resource while allowing for the adequate usage. 


\section{References}

Alessa, L., Bennett, S. M., Kliskey, A. D. (2003). Effects of Knowledge, Personal Attribution, and Perception of Ecosystem Health on Depreciative Behaviours in the Intertidal Zone of the Pacific Rim National Park and Reserve. Journal of Environmental Management. 68, 207-218.

Attarian, A. 1998. An Overview of Rock Climbing in New River Gorge National River [technical report]. Golden, CO: American Alpine Club.

Borrie, W., \& Harding, J. (2002). Effective Recreation Visitor Communication Strategies: Rock Climbers in the Bitterroot Valley, Montana. USDA Research Note RMRS-RN-15.

Bradford, L., \& McIntyre, N. (2007). Off the Beaten Track: Messages As A Means Of Reducing Social Trail Use At St. Lawrence Islands National Park. Journal of Park and Recreation Administration, 25(1), 1-21.

Cole, D.N., Watson, A. E., Hall, T. E., \& Spildie, D. R. (1997). High-Use Destinations in Wilderness: Social and Biophysical Impacts, Visitor Responses, and Management options. USDA Forest Service - Research Paper INT-RP-496.

Georgiade, N. C. (2005). Impact of Site Decision Variables on Visitors' Choices of State and Federal Rock Climbing Areas. Unpublished master's thesis, North Carolina State University.

Gilbertson, K. (2002). Determining Baseline Behaviors of Rock Climbers Toward Protecting Resource Degradation. Unpublished Manuscript.

Hughes, M., Ham, S., \& Brown, T. (2009). Influencing Park Visitor Behavior: A Belief-based Approach. Journal of Park and Recreation Administration, 27(4), 38-53.

Jones, C. D., Hollenhorst, S. J., \& Hammitt, W. E. (2004). Assessing the Social Construction of Visual-Spatial Preferences for Wilderness Impacts. Journal of Park and Recreation Administration. 22(3), 59-68.

Larson, D. W., Matthes, U., \& Kelly, P. E. (2005). Cliff Ecology: Pattern and Process in Cliff Ecosystems. New York, NY: Cambridge University Press.

Leopold, A. (1949). A Sand County Almanac. New York: Oxford University Press.

Manning, R., \& O’Dell, I. (1997). Social Carrying Capacity of Parks and Outdoor Recreation Areas. Parks and Recreation. 32(10), 32-38.

Manning, R., Jacobi, C., \& Marion, J. (2006). Recreation Monitoring at Acadia National Park. The George Wright Forum, 23(2), 59-72. 
Marion, J., \& Leung, Y. (2001). Trail Resource Impacts and An Examination of Alternative Assessment Techniques. Journal of Park and Recreation Administration, 19(3), 17 37.

Marion, J., Leung, Y., \& Nepal, S. (2006). Monitoring Trail Conditions: New Methodological Considerations. The George Wright Forum. 23(2), 36-49.

Marion, J. (October 2007). Assessment of Recreation Impacts to Trails and Cliffs in the Potomac Gorge - Progress Report. USGS.

Monz, C., Smith, K., \& Knickerbocker, L. (2005). Climbers' Attitudes Toward Recreation Resource Impacts in the Adirondack Park. Proceedings of the 2005 Northeastern Recreation Research Symposium.

Monz, C. (2009). Climbers' Attitudes toward Recreation Resource Impacts in the Adirondack Park's Giant Mountain Wilderness. International Journal of Wilderness, 15(1), 26-33.

National Park Service. 2002. Final Climbing Management Plan. Obed Wild and Scenic Rover. 21p.

National Park Service, 2005. Climbing Management Plan: Environmental Assessment. New River Gorge National River. 200p.

National Park Service. 2009. Draft Foundation for Planning and Management. New River Gorge National River. 64p.

National Park Service. 2011. Draft Director's Order \#41: Wilderness Stewardship. 13p.

Nepal, S. K., \& Nepal, S. A. (2004). Visitor Impacts on Trails in the Sagarmatha (Mt. Everest) National Park, Nepal. Ambio, 33(6), 334-340.

Nuzzo, V. (1995). Effects of Rock Climbing on Cliff Goldenrod (Solidago sciaphila Steele) in Northwest Illinois. American Midland Naturalist, 133(2), 229-241. Retrived May 3, 2009, From JSTOR database.

Pettebone, D., Newman, P, \& Theobald, D. (2009). A Comparison of Sampling Designs for Monitoring Recreational Trail Impacts in Rocky Mountain National Park. Environmental Management, 43, 523-532.

R Development Core Team, (2011). R: A Language and Environment for Statistical Comuting. R Foundation for Statistical Computing. Vienna, Austria. http://www.Rproject.org, ISBN 3-900051-07-0.

Ramthun, R., \& A. Blake. (2002). Exploring Quality Standards for New River Gorge Climbing Sites: Establishing a Baseline for the Future. In: Schuster, Rudy, comp., ed. 
Proceedings of the 2002 Northeastern Recreation Research Symposium. Gen. Tech. Rep. NE-302. Newtown Square, PA: U.S. Department of Agriculture, Forest Service, Northeastern Research Station. 87-89.

Schuster, R., Thompson, J, \& Hammitt, W. (2001). Rock Climbers' Attitudes Toward Management of Climbing and the Use of Bolts. Environmental Management, 24(3), 403-412.

Siderelis, C., \& Attarian, A. (2004). Trip Response Modeling of Rock Climbers' Reactions to Proposed Regulation. Journal of Leisure Research, 36(1), 73-88.

Walker, G., Parisher, E., Smith, P., Whitlock, D., Kramar, D., Matthes, U., \& Morefield, L. (2004). Characterization of Plant Community Structure and Abiotic Conditions on Climbed and Unclimbed Cliff Faces in the Obed River Gorge. Unpublished manuscript.

Wood, K. T. (2006). Assessing Recreation Impacts to cliffs in Shenandoah National Park: Integrating Visitor Observation with Trail and Recreation Site Measurements. Unpublished master's thesis, Virginia Polytechnic Institute and State University.

Wood, K. T., Lawson, S., \& Marion, J. (2006). Assessing Recreation Impacts to cliffs in Shenandoah National Park: Integrating Visitor Observation with Trail and Recreation Site Measurements. Journal of Park and Recreation Administration, 24(4), 86-110. 
Cliff User Observation Data Sheet - New River National River (NERI)

Observer:

Date: / /

Location:

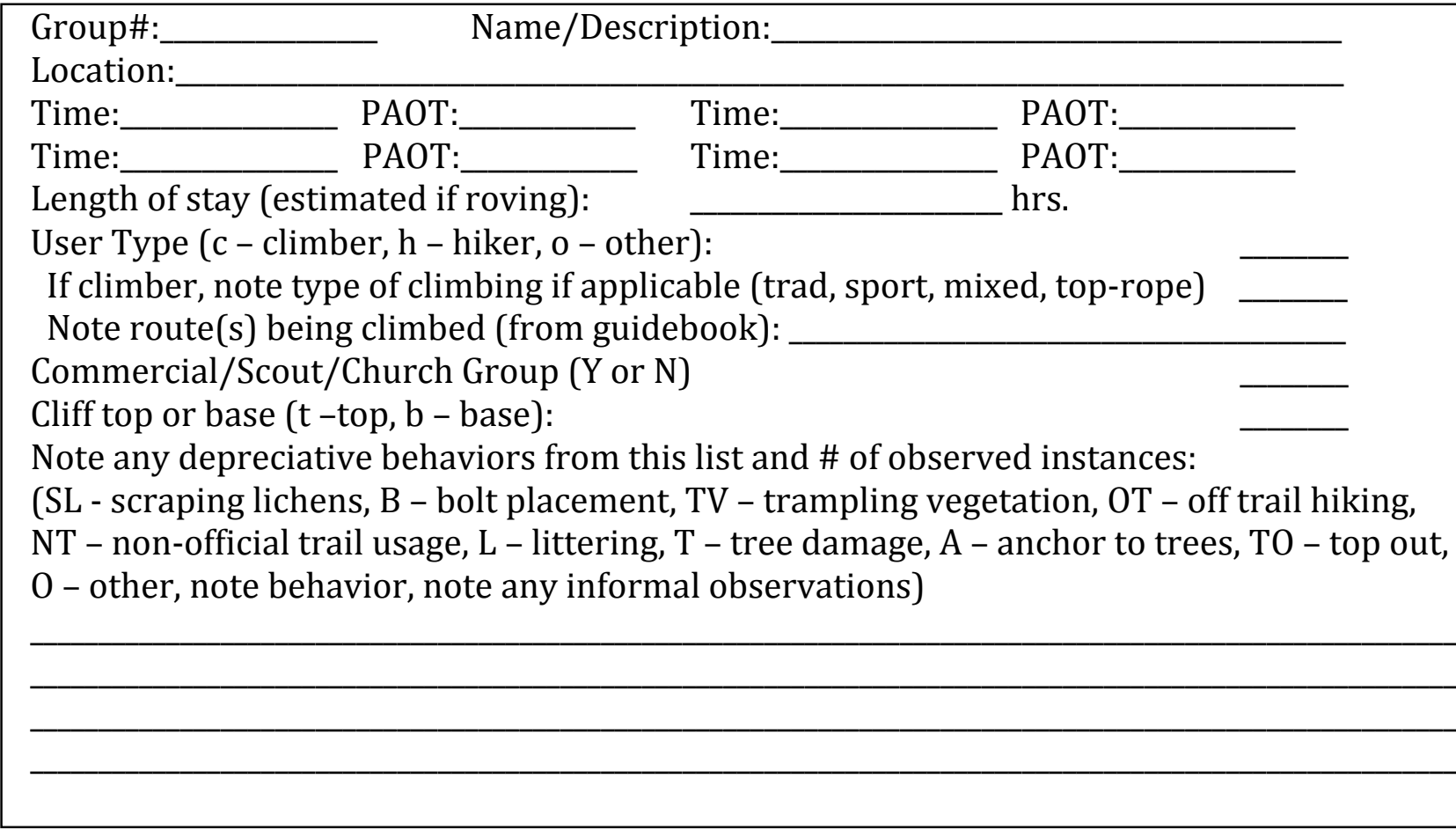

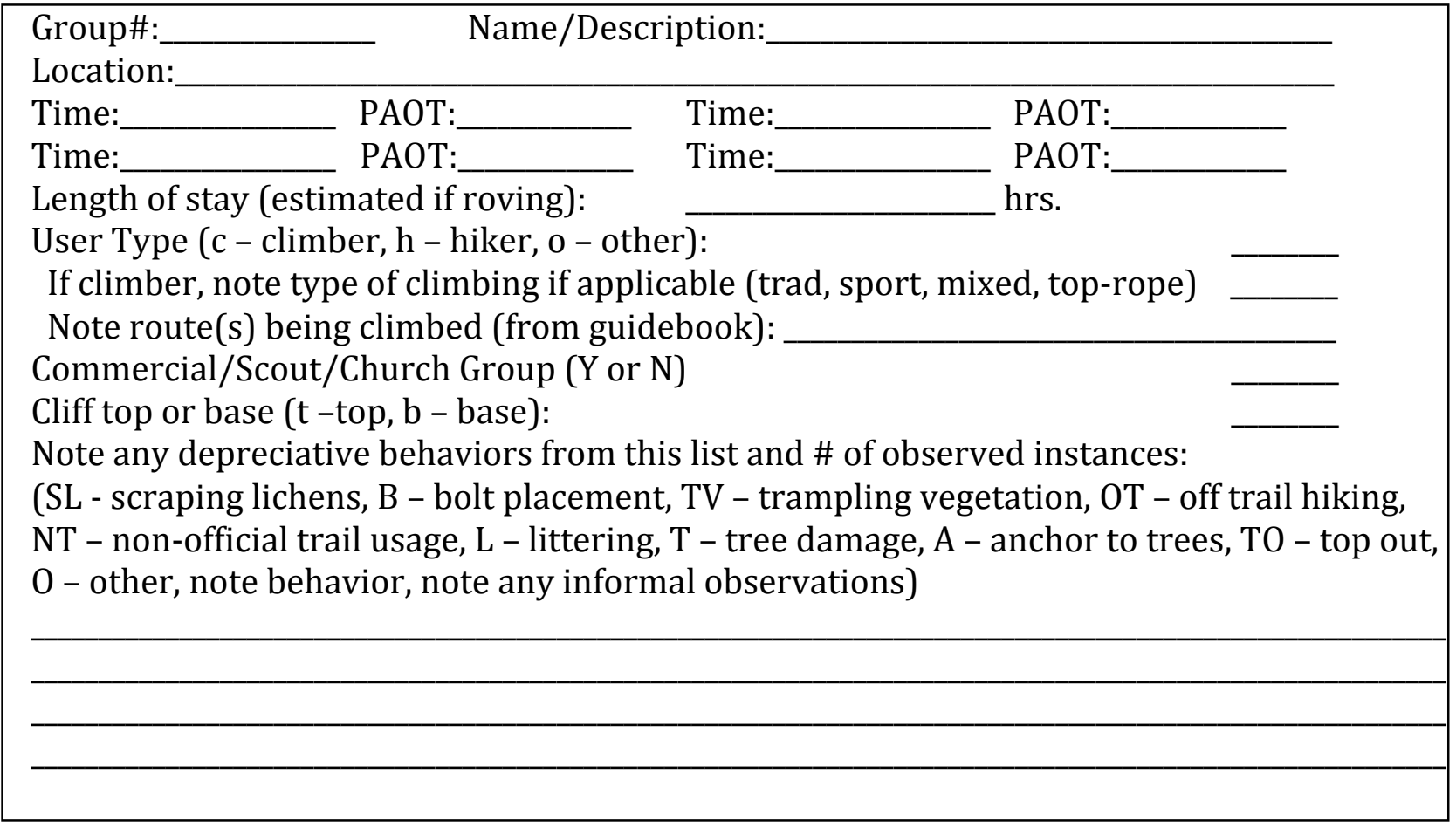




\section{Kyle Olcott}

45 Wade Street

Morgantown, WV 26501

(304) 932-3733

olcottdk@gmail.com

\section{Education:}

West Virginia University, Morgantown, West Virginia

M.S., Forestry, Recreation, Parks and Tourism Resources concentration

Expected completion in May, 2011

Thesis: Understanding Cliff Use at the New River Gorge National River: Combining

Visitor Observations and Resource Impact Assessments

Washington and Lee University, Lexington, Virginia

B.A., Philosophy

June, 2005

Skills:

SPSS and R statistical packages

ESRI ArcMap and ArcPad GIS software

Adobe InDesign and Photoshop software

\section{Research Interests:}

Recreation behavior, recreation ecology, wilderness ethics, sustainable tourism

\section{Related Employment History:}

Research Assistant, West Virginia University, January 2010-Present Assisting Dr. Dave Smaldone with a National Park Service funded, cross-disciplinary, multi-year study of the cliff resource at the New River Gorge National River. Responsible for field data collection, field mapping, methods development, data analysis, and report writing pertaining to the recreation component of the project.

\section{Awards/Honors:}

Eagle Scout, Boy Scouts of America, 1998

References available upon request 